IZA DP No. 8490

When the Baby Cries at Night:

Inelastic Buyers in Non-Competitive Markets

Giacomo Calzolari

Andrea Ichino

Francesco Manaresi

Viki Nellas

September 2014 


\title{
When the Baby Cries at Night: Inelastic Buyers in Non-Competitive Markets
}

\author{
Giacomo Calzolari \\ University of Bologna and CEPR \\ Andrea Ichino \\ European University Institute, CEPR, IZA and CESifo \\ Francesco Manaresi \\ Bank of Italy \\ Viki Nellas \\ University of Bologna
}

Discussion Paper No. 8490
September 2014

IZA

P.O. Box 7240

53072 Bonn

Germany

Phone: +49-228-3894-0

Fax: +49-228-3894-180

E-mail: iza@iza.org

Any opinions expressed here are those of the author(s) and not those of IZA. Research published in this series may include views on policy, but the institute itself takes no institutional policy positions. The IZA research network is committed to the IZA Guiding Principles of Research Integrity.

The Institute for the Study of Labor (IZA) in Bonn is a local and virtual international research center and a place of communication between science, politics and business. IZA is an independent nonprofit organization supported by Deutsche Post Foundation. The center is associated with the University of Bonn and offers a stimulating research environment through its international network, workshops and conferences, data service, project support, research visits and doctoral program. IZA engages in (i) original and internationally competitive research in all fields of labor economics, (ii) development of policy concepts, and (iii) dissemination of research results and concepts to the interested public.

IZA Discussion Papers often represent preliminary work and are circulated to encourage discussion. Citation of such a paper should account for its provisional character. A revised version may be available directly from the author. 


\section{ABSTRACT \\ When the Baby Cries at Night: Inelastic Buyers in Non-Competitive Markets*}

We investigate empirically how sellers react to changes in the population of their consumers, identifying the effects of demand composition and demand size with limited information on costs. We show how pharmacists in Italy selectively increase the price of some products when they observe in their cities an exogenous influx of parents of newborns, conceivably less elastic buyers as compared with other more experienced and less pressed consumers. Exploiting population based laws that fix the number of pharmacies in a city, we use RDD to measure the effect of competition on sellers' ability to extract surplus from less elastic buyers.

JEL Classification: D43, D83, L13

Keywords: demand elasticity, consumer's information, price competition, pharmacies, regression discontinuity

Corresponding author:

Andrea Ichino

Department of Economics

European University Institute

Via Piazzola 43

50133 Firenze

Italy

E-mail: andrea.ichino@eui.eu

\footnotetext{
"We thank the software house that provided the data on pharmacies used in this study. We also thank ANPI (in particular, Massimo Brunetti) for the data on "Parafarmacie" and ISTAT (in particular Saverio Gazzelloni and Angela Silvestrini) for the demographic data. We received insightful comments from Marco Alderighi, Joshua Angrist, Chiara Fumagalli, Paul Heidhues, Peter Kuhn, Saul Lach, Jose Moraga-Gonzalez, Claudio Piga, Andrea Pozzi, Fernando Vega-Redondo, Giulio Zanella and seminar participants at the Bank of Italy, BCLE, Bologna, EUI, Lech am Arlberg, MACCl Conference 2012 Mannheim, St. Gallen, Stockholm School of Economics, UPF, Warwick, University of Montreal and Boston University to whom our gratitude goes.
} 


\section{Introduction}

In some periods of their life consumers may enter markets that they know less well and/or may face a higher opportunity cost of their time. Both these changes, for example, characterize what happens when they become parents of newborns. In such cases consumers often cannot acquire immediately all the useful information about the best prices in the new market they just entered and about the relevant products needed by their babies. They may also have less time to profit from the best deals even if they had all the information necessary to identify them. As a consequence, these consumers are less price sensitive than standard and more experienced ones. Similar kinds of buyers' heterogeneity, in terms of price elasticity, are likely to be a common feature of most markets, but their consequences on firms' actual pricing strategies are relatively unexplored.

In this paper we investigate how firms react to changes in the composition of their consumers, specifically when they perceive that the proportion of less elastic buyers increases. Theory predicts that in this case sellers raise prices to expand surplus appropriation, even if marginal costs are non-increasing, but this effect weakens as market competition intensifies. While the theory is pretty straightforward and uncontroversial, the empirical challenge of this investigation originates from the fact that changes in composition are typically associated with changes in the size of demand shocks and without knowing whether marginal costs are increasing, constant or decreasing, one cannot attribute observed price increases to increasing marginal costs or to a change in demand composition in the presence of market power. Disentangling the effects of demand composition and demand size with limited information on firms' costs (as it is often the case and we are no exception) has therefore proven to be difficult in the literature.

We solve this problem using data on the number of newborn babies at the monthly frequency between January 2005 and December 2010 for each of the 8,092 Italian municipalities (henceforth, cities). Controlling for city and time fixed effects, the variation in newborns at the monthly frequency is arguably random and captures a demand shock with potentially different effects on products that are demanded by newborn parents only (like diapers and milk powder) or by other consumers as well (like child hygiene goods which are demanded 
also by adults for their own personal usage). In the case of diapers and milk powders, since newborn parents are the only and homogeneous group of buyers, a birth rate increase at the city level represents a demand shock that leaves unchanged the price elasticity of the average customer. Thus, for these products the price will increase (decrease) only if marginal costs are increasing (decreasing). In the case of hygiene products, instead, the same demand shock caused by newborns babies can change the composition of buyers in terms of elasticity if newborn parents differ from other buyers. The resulting price change will therefore incorporate both the composition effect due to market power and the scale effect due to the shape of marginal costs.

Under the reasonable assumption that the shape of marginal costs is similar for the three products (we will actually show evidence that this is the case and that, if anything, marginal costs are more decreasing for hygiene products) the difference between the effects induced by newborns' random fluctuations on the price of hygiene goods with respect to the price of diapers and milk powders is a lower bound for the measure of the composition effect on prices due to exogenous waves of hurried, less informed, and thus less elastic buyers.

Our analysis rests on the debatable assumption that immediately after delivery parents suddenly enter as buyers in the market of the goods that are necessary to raise their babies, but do not know well (yet) their children's needs and are relatively less informed about prices than other consumers of those products, including parents of older babies. Newborn parents may also be more frequently under pressure (... when the kid cries!), thus facing a high opportunity cost of time to search and being less able to profit from the best offers available in the market. This assumption is debatable because it is possible to argue that newborn parents are no different than other consumers or even less rigid if they have more time to search thanks to parental leaves, but, as we will see, the data are definitely more consistent with our (... introspective) prior.

The insights of the theoretical model that guides our analysis invite us to further explore empirically whether the composition effect, that we estimate in the first part of the paper, decreases when competition among sellers increases. To do this, we need exogenous sources of variation in the number of sellers. We find these sources by concentrating the analysis on cities whose maximum population during the last 45 years has been in a neighborhood of the 
7500 units threshold. Indeed, the Italian law prescribes, similarly to many other countries, that cities with a population lower than this threshold should have only one pharmacy, while an additional pharmacy should be opened in cities above the threshold. With respect to current population, there is substantial non-compliance with this rule, partly because of geographic reasons, ${ }^{1}$ but more importantly because during the post-war period, when population grew above the threshold, pharmacies were opened but later they were not closed if population declined under the threshold. Precisely for this reason, the maximum population size reached historically by cities generates a fuzzy assignment mechanism for the current number of pharmacies. We exploit this assignment mechanism in a Regression Discontinuity Design to study how the number of sellers influences the effect of an increase in newborns on different product prices.

We first show that, as expected, cities immediately above the threshold (in terms of maximum historical population) have, on average, a larger number of pharmacies than cities immediately below it (i.e. the instrument is not weak). More interestingly, we then show that, in the case of hygiene products, where the number of competing pharmacies is small for this exogenous reason, the elasticity of equilibrium prices to newborns is significantly positive, while it falls to zero where competition is more intense. In the case of diapers and milk powders, instead, the analogous elasticity does not change at the threshold and is always not different from zero independently of the number of competing pharmacies. We interpret these findings as evidence that, in less competitive environments and for products characterized by heterogeneous buyers, sellers can exploit to their advantage increases of demand originating from less elastic consumers. However, when competition increases, sellers' ability to exploit this type of market power is severely limited.

Although there has been a recent surge of empirical investigations of consumers' heterogeneity, these studies typically do not address directly the composition effect on prices which emerges when, for some reasons, the relative proportion of different types of consumers changes. An important exception is Lach (2007) who studies the effect of an unexpected large inflow of immigrants to Israel during 1990. He shows that a one-percentage-point in-

\footnotetext{
${ }^{1}$ The presence of remote areas or valleys and rivers within the city boundaries is the most common motivation for being allowed to have more pharmacies than what the demographic criterion would prescribe.
} 
crease in the ratio of immigrants to natives in a city decreases prices of commodity goods by 0.5 percentage points. He explains this finding with immigrants having lower search costs and higher price elasticity than the native population, under the maintained assumption that marginal costs are not decreasing for the firms he considers. We study instead an increase in less price-elastic and higher-search costs consumers (the parents of newborns), but at the same time we are able to explicitly net out possible effects of non-constant marginal costs. We show that this shock has a positive effect on the price of goods for which the composition of demand changes. ${ }^{2}$ In addition to tackling explicitly the problem of marginal costs, we improve with respect to Lach (2007) because he does not study how competition among sellers modifies the effect of an inflow of buyers characterized by a different price elasticity. We show instead, in a Regression Discontinuity Design, that greater competition reduces the capacity of sellers to extract surplus from less elastic buyers.

Search related effects of consumers' heterogeneity are also studied in Aguiar and Hurst (2007). Using scanner data, they have shown that older individuals, facing a lower opportunity cost of time, shop more frequently looking for temporary discounts. They thus end up paying lower prices than younger consumers for exactly the same products. Interestingly for our analysis, Aguiar and Hurst (2007) are able to calculate the implicit opportunity cost of time, showing that it is hump shaped with respect to age, with a peak in the early thirties, precisely when most of them are engaged in parental care. This empirical observation is consistent with our findings but, differently from their paper, we do not take shops' pricing strategies as given. We verify if and how shops endogenously modify prices when they observe a change in the composition of customers.

Addressing the role of frequency of purchase and consumers' information, Sorensen (2000) finds that the price dispersion and the price-cost margin for a prescription drug are negatively correlated with the frequency of usage. Higher frequency of dosage allows consumers to become more informed on the prices available in the market for these drugs and phar-

\footnotetext{
${ }^{2}$ Lach (2007) compares as well different elasticities of the immigrant effect for different groups of products showing stronger negative effects for the prices of those products characterised by a larger share of consumers that are immigrants. However, these results may be, at least in part, due to non-constant marginal costs. For example, Lach (2007) notices that because of religious dietary restrictions, pork meat was a very small market in Israel before the arrival of Russian immigrants who conceivably induced a significant scale effect and, possibly, an associated cost reduction.
} 
macies respond by reducing price-cost margins and price variation on these products. We differentiate from this paper by studying differences in consumers not in products and by addressing the important role of competition as well.

The advent of Internet has been seen as one leading factor that has reduced search costs, increased the fraction of more informed consumers, and ultimately induced a reduction of prices. This has been documented, for example, by Brown and Goolsbee (2002) illustrating the effect of Internet comparison-shopping sites on the prices of life insurance in the 1990s. In the mutual funds industry, Hortacsu and Syverson (2004) document an upward shift of the estimated search costs distribution for heterogeneous investors that occurred between 1996 and 2000 and suggest, with indirect evidence, that this observation may be the result of entry of novice investors. ${ }^{3}$ Similarly to these papers, we are interested in measuring the composition effect in markets with consumers characterized by different levels of elasticities, possibly induced by different available information sets and higher time pressure. However, and differently from these papers, we address this analysis with a direct measure of an exogenous change in the composition of consumers, offered by the possibility to count explicitly the number of inexperienced parents of newborns entering the market for childcare products. We further quantify this composition effect by interacting it with an exogenous source of variation in the market structure, i.e. the number of pharmacies available to parents as implied by the law.

In our environment, a similar composition effect is observed by the econometrician under different pricing strategies adopted by pharmacists and we are not interested in disentangling these different possibilities. These sellers may react to a change in the composition of buyers by raising the single price optimally chosen for the average customer, in order to extract more surplus from the larger fraction of less elastic buyers, i.e. the parents of newborns. Alternatively, if shops' products are sufficiently substitutable, the presence of groups of consumers characterized by different price elasticities may induce sellers to rely on mixed strategies; also in this case, a change in the composition of buyers would shift firms' incentives towards surplus-appropriation instead of business stealing, producing a different mixed strategy equilibrium with high prices being employed with higher probability. Or,

\footnotetext{
${ }^{3}$ However, they say on p. 441: "We emphasize that our model's implication of such a composition shift is only suggestive-we would need investor-level data to test it definitively".
} 
finally, pharmacists may engage in price discrimination, which occurs if they charge higher prices to less elastic buyers or sell at a discount to more experienced and elastic consumers. If a pharmacist charges those different prices, an increase of the number of newborns, in a city and in a given month, determines an increase of the average price observed by the econometrician in that city and month. Although mainly interested in identifying and measuring market power, Graddy (1995) studies the NY Fulton fish market, showing that Asian buyers pay more than white buyers for similar products. In our environment, we cannot identify the individual characteristics of each single buyer and thus we cannot test explicitly for the presence of price discrimination, as Graddy (1995) does.

The rest of the paper is organized as follows. Section 2 provides the theoretical background that guides our empirical exercise. Section 3 describes the data and illustrates the identification strategy. Section 4 presents and discusses the effect of newborns on the equilibrium price of the three types of products (diapers, milk powders and hygiene goods). Section 5 shows instead how competition affects the elasticities estimated in the previous Section. Finally, Section 6 concludes.

\section{Theoretical insights}

Consider a market with $S$ shops (pharmacies), each one selling two possibly differentiated products, namely product $H$ (hygiene product) and product $D$ (diapers or milk powders). ${ }^{4}$ At any period $t$, product $H$ is purchased by a total of $N_{t}$ consumers of two groups $j=A, B$ (respectively adult consumers and parents of babies), with $N_{t}^{j}$ being the number of consumers of group $j$. Each buyer of group $j$ has an individual demand $q_{H i}^{j}$ for product $H$ at shop $i$ and a price elasticity $\eta_{H i}^{j}$. We will state that group $j$ is more price sensitive or elastic than group $j^{\prime}$ if, for any price, $\eta_{H i}^{j}>\eta_{H i}^{j^{\prime}}$. Product $D$ is purchased uniquely by consumers of group $B$ with individual quantity $q_{D i}^{B}\left(\right.$ clearly, $\left.q_{D i}^{A}=0\right)$. The number $N_{t}^{j}$ of consumers $j$ at any $t$ is a IID random variable independent from that of consumers $j^{\prime} .{ }^{5}$ The cost $C\left(Q_{i}\right)$ for total sales

\footnotetext{
${ }^{4}$ The Appendix A.1 for online publication derives formally the results of this section illustrating equilibrium prices and the relevant comparative statics in an explicit model.

${ }^{5}$ Our empirical analyses will account for the possibility that some consumers in the group $B$ enter group $A$ after a while.
} 
$Q_{i}$ of the two products for shop $i$ is time invariant. ${ }^{6}$ Shops do not price discriminate and the price of product $g$ in shop $i$ at time $t$ is $p_{i g t} .^{7}$

In the rest of this section we show that, inasmuch as newborn parents are not like other buyers, a change in their number has different effects on the price of product $H$, which is demanded by both types $A$ and $B$ of consumers than on the price of product $D$, which is instead of interest to $B$ consumers only.

The profit of shop $i$ at date $t$ is

$$
\pi_{i t}=\sum_{j, g} p_{i g t} \times q_{i g t}^{j} \times N_{t}^{j}-C\left[\sum_{j, g} q_{i g t}^{j} \times N_{t}^{j}\right] .
$$

where $q_{i g t}^{j}$ is the demand of product $g$ at time $t$ and shop $i$ expressed by a consumer of type $j$. Let $M R_{i g t}^{j}$ be the per-consumer of type $j$ marginal revenue on product $g$. The optimal prices $p_{i D t}$ and $p_{i H t}$ must satisfy the usual necessary conditions: for price $p_{i D t}^{*}$

$$
M R_{i D t}^{B} \times N_{t}^{B}=C^{\prime}\left(Q_{i t}\right) \times N_{t}^{B}
$$

and for price $p_{i H t}^{*}$

$$
M R_{i H t}^{A} \times N_{t}^{A}+M R_{i H t}^{B} \times N_{t}^{B}=C^{\prime}\left(Q_{i t}\right) \times N_{t}
$$

The difference in these two optimality conditions is the consequence of product $D$ being purchased by consumers $B$ only and product $H$ being instead of interest to both consumers $A$ and $B$.

We are interested in how the prices of the two products $H$ and $D$ are affected by a change in the composition of the population of consumers, i.e. the ratios $N_{t}^{j} / N_{t}$. Consider first the simpler case of a constant marginal cost, $C^{\prime}\left(Q_{i t}\right)=\mathcal{C}$. Condition (2) immediately implies that the optimal price of product $D$ does not depend on $N_{t}^{B}$, nor on $N_{t}$ and on the the composition of the population of consumers. Shop $i$ simply sets an optimal price

\footnotetext{
${ }^{6}$ With no effects on our results but at the cost of complicating notation, one could add product specific costs such as different wholesale prices paid by shops to procure the products.

${ }^{7}$ Price discrimination would not qualitatively alter our result. The average price observed by the econometrician at a given time in a given shop would vary with the composition of the population of consumers: a relative increase of the number of elastic consumer would put more weight on the lower price designed for those consumers.
} 
that maximizes the per-consumer (of type $B$ ) profit. The analysis on product $H$ is more articulated because the population of consumers for this product is heterogeneous and the optimal price defined by condition (3) now does depend on the composition $N_{t}^{j} / N_{t}$ of the population. In particular, if consumers $B$ are less elastic than those in group $A$, then a larger fraction $N_{t}^{B} / N_{t}$ of inelastic consumers increases the average price, a composition effect. At the same time, any change in the total number of consumers $N_{t}$ that leaves unaffected the proportions of the two types of consumers $N_{t}^{A} / N_{t}$ and $N_{t}^{B} / N_{t}$, would have no effect on the average price.

Moving to the more realistic case of non-constant marginal costs, it becomes difficult to disentangle the composition and the scale effects for product $H$ if this product is considered separately and independently of the others. Suppose in fact that marginal costs are upward sloping. An increase of the population $N_{t}$ associated with a larger fraction $N_{t}^{B} / N_{t}$ of inelastic consumers would increase the observed average price defined by condition (3) both because of the changed composition of consumers and because of the scale effect induced by increasing marginal costs. Similarly, with decreasing marginal costs, an increase in the fraction of elastic consumers would induce a reduction of the price of product $H$, but it would still not be obvious how to disentangle this effects into the composition and scale components.

However, it is possible to solve the problem by comparing how the price of different products respond to similar changes in the population of consumers. In particular, one can rely on changes in $N_{t}^{B}$ which in our empirical analysis correspond to changes in the number of newborns. Since product $D$ is only purchased by consumers $B$, a change in the number $N_{t}^{B}$ of these consumers can only affect the price of product $D$ if marginal costs are nonconstant. Given that this same scale effect would take place also for the price of the other product $H$, if we do not observe a differential impact on the prices of the two goods, then we can conclude that the two types of consumers are characterized by the same elasticity. If we observe instead a significant differential effect of changes in the number of newborns on the two prices, the sign and dimension of the differential effect will speak about the relative elasticity of the two groups of consumers $A$ and $B$ and about the capacity of the sellers to exploit their market power.

The following remark (which is formally proven in the model described in Appendix A.1 
for on line publication) summarizes these possibilities.

Remark 1 (Composition effects) Consider a market with $N_{t}^{B}$ type B-consumers, buying both products $D$ and $H$, and with $N_{t}^{A}$ type A-consumers, who instead buy only product $H$.

1.1) The price of product $D$ is unaffected by an increase of the number $N_{t}^{B}$ of its consumers if and only if the marginal costs are constant and it increases (decreases) if and only if marginal costs are increasing (decreasing).

1.2) Keeping constant $N_{t}^{A}$, an increase of the number $N_{t}^{B}$ of consumers $B$ has a differential effect on the prices of the two products:

$$
\frac{\partial p_{i H t}^{*}}{\partial N_{t}^{B}}>\frac{\partial p_{i D t}^{*}}{\partial N_{t}^{B}}
$$

if and only if consumers $B$ are less elastic than consumers $A$.

Under Remark 1.2 we should expect that competition limits the possibility of sellers to exploit their market power and therefore that the differential impact on prices induced by a change in $N_{t}^{B}$ is reduced (in absolute value) by a larger number $S$ of shops. The effect of competition on the composition effect is summarized in the following remark:

Remark 2 (Competition on composition effect) The differential effect on prices of an increase of the number $N_{t}^{B}$ of consumers B, implied by Remark 1.2, is mitigated by competition, i.e. the difference

$$
\left|\frac{\partial p_{i H t}^{*}}{\partial N_{t}^{B}}-\frac{\partial p_{i D t}^{*}}{\partial N_{t}^{B}}\right|
$$

is decreasing in $S$.

\section{The data and the empirical strategy}

We use information on a large sample of Italian pharmacies collected by "Pharma" (the name is fictitious for confidentiality reasons), a consultancy company for pharmacies and 
pharmaceutical firms. ${ }^{8}$ With the consent of its clients, we were given access to the details of every item sold by each pharmacy in the Pharma database for the period from January 2007 to December 2010. The dataset originates from each single sale receipt. During the period under study, Pharma collected data from 3,331 Italian pharmacies, corresponding to $18.6 \%$ of the universe of pharmacies in Italy. For $60 \%$ of them, we have complete information for the entire period; for $28.7 \%$ we have information starting from January 2009; and for the remaining $11.26 \%$ data is available only for the period January 2007-December 2008. The pharmacies in the Pharma database are located in almost all the Italian regions (with the exception of Basilicata), but their concentration is higher in the North since the company is located near Milan. ${ }^{9}$

Our goal is to use this dataset to test the theoretical predictions of Section 2, summarized in Remarks 1 and 2, concerning how, in a market, prices (and quantities) are affected by a demand shock that changes the composition of consumers with respect to price elasticity, at different levels of competition between sellers. We argue that a measure of this kind of shock for a subset of products sold by these pharmacies is represented by changes at the monthly frequency of the number of newborns in the neighborhood where a pharmacy is located. ${ }^{10}$ Monthly data on newborns are obtained at the city level from the National Statistical Office (ISTAT). The left panel of Figure 1 plots the temporal evolution of the number of newborns in the cities where the pharmacies of the Pharma sample operate. On average, there are 19 newborns per month in a city, but there is a significant seasonality: the most relevant peaks are typically in the summer, while the lowest levels are more frequent in the winter.

\footnotetext{
${ }^{8} \mathrm{~A}$ pharmacy in Italy is a shop selling prescription drugs (with regulated prices), OTC drugs (some with unregulated prices) and health related products (all with unregulated prices which pharmacists can change at their will) such as those analyzed in this paper. They are typically run as a family business and are very profitable due to restricted entry.

${ }^{9}$ Specifically $19 \%$ of these pharmacies are in the north east of Italy, $45 \%$ in the north west, $9 \%$ in the center, $16 \%$ in the south and $11 \%$ in the islands.

10 Ideally, in our empirical analysis we would have liked to use information on the number of newborn babies who are the first children in their families, but this statistic is not available. However, given the relatively low fertility rate in Italy (which hovered between 1.28 and 1.40 during this period) and the fact that children are fairly evenly distributed across households, the probability that a generic newborn is the first child in a family is around $46 \%$ in 2010 according to the Bank of Italy Survey of Household Income and Wealth. Therefore, under the extreme assumption that parents are "different" buyers only at their first birth experience, slightly less than $50 \%$ of the shock that we measure at the city level captures a change in the composition of customers. In this case, our estimates of the effects of a change in the number of all newborns at the city level could be interpreted as lower bounds of the actual effects.
} 
The right panel of the Figure plots the residuals of a regression of (log) newborns on city fixed effects. These residuals show a substantial within-city and over time variability in the number of newborns.

Ideally, we would like to measure the monthly number of newborns in some neighborhood of each pharmacy, but we can only measure it at the level of a city. Therefore in the empirical analysis we aggregate all the pharmacies of the Pharma data set in each municipality and consider as a unit of observation the average price and the average quantity sold by these pharmacies in each city. Every city will thus be a market like the one described in Section 2. Note that unfortunately we do not observe the quantity and the price of the pharmacies that, within each city, are not in the Pharma sample. This is unfortunate, but we will report results restricted to cities in which we observe all the existing pharmacies (i.e. cities in which Pharma has a full market coverage), to show that our results remain unaffected.

We select three categories of products of which the first one (child hygiene) is the empirical counterpart of the type $H$ product of the theoretical model described in Section 2 and is demanded by newborn parents for their babies as well as by other categories of buyers. The other two products instead (diapers and milk powders) are demanded only by newborn parents, like product $D$ in the theoretical model. Therefore, only in the case of hygiene products there is a chance that the demand shock caused by newborns can change the composition of buyers in terms of elasticity, if newborn parents differ from other buyers. For the other two types of products, newborns can only have a scale effect with no change in composition. Descriptive statistics are in Table $1 .^{11}$

Specifically, the products that are demanded by an homogenous set of consumers only (parents of newborns) are 2007 types of diaper and 427 types of milk powder. ${ }^{12}$ The hygiene category, instead comprises 3039 products that are primarily (but not only) used for children immediately after birth and then extensively during the first years of their life. ${ }^{13}$ Parents of

\footnotetext{
${ }^{11}$ Additional statistics for the most frequently sold and most highly priced items in each basket are reported in Table A.2.1 of the Appendix for online publication.

${ }^{12}$ In some cities, pharmacies do not sell milk powder, possibly because of breast-feeding preferences. For this reason, as shown in Table 1 , the number of city $\times$ month observations for milk products sales differs from the number of city $\times$ month observations for hygiene products and diapers sales.

${ }^{13}$ This set includes items (of different brands) like: bath foams and shampoos for babies; cleansers for babies; cold and barrier creams and oils for babies; baby wipes; talcum and other after-bath products for babies.
} 
newborns are buyers of these hygiene products and, like type $B$ consumers of the theoretical model, may have a higher (opportunity) cost of search because they are time-constrained and may be relatively inexperienced about the new market in which they just entered. The opposite is also possible in principle, in the sense that they could alternatively have more time to search for the best deal, for example because of maternity leave, but the data are definitely consistent with the first hypothesis, as we will see. In any case they conceivably differ from other buyers of these hygiene products like, for example, sportsmen who are heavy users of ointments for child skin protection, while shampoos, bath foams, and barrier creams for children are used by other adults as well. These various groups of adult buyers, different than parents, represent the empirical counterpart of the type $A$ consumers described in the theoretical model of the previous section.

Since the data come from actual till-receipts, and not from posted prices, the price $p_{i k t g}$ is only observed if there is at least one transaction in period $t$ involving product $k$ of category $g=\{$ Hygiene, Diaper, Milk $\}$ in pharmacy $i$. For items that have not been sold for an entire month in a given pharmacy, the price imputed is the price of the first subsequent transaction of the same item observed for the same pharmacy in a subsequent month. When the sold quantity is positive, instead, the monthly price is the weighted average of the (possibly) different prices actually charged over the month, with weights equal to the number of items sold at each price level. ${ }^{14}$

For the econometric analysis we aggregate the products in each of the three categories $g=\{$ Hygiene, Diaper, Milk $\}$ into three baskets and we construct corresponding Laspeyres indexes of prices and quantities. Denoting with $k \in 1, \ldots, K_{g}$ each product in a basket, and with $p_{i k g t}, q_{i k g t}$ respectively the price and the quantity at pharmacy $i$ and at month $t$ for product $k$ in basket $g$, the price and quantity indexes (hereafter, price and quantity) for

\footnotetext{
14 The imputation of prices in months when no transaction is observed may bias our estimates of the effect of newborns on prices, probably downward. This hypothesis is supported by the fact that if we restrict the analysis to the subset of items that are sold at least once in each month, and therefore for which no imputation is needed, estimates of the effect of newborns on the price of child hygiene products are slightly larger in size and equal in significance (estimates for diaper and milk prices remain not significantly different from zero). Moreover, consider the hypothetical situation in which there are transactions at a low price in period $t$, there are no transaction in period $t+1$ and there are again transactions in period $t+2$ at a high price induced by an increase in newborns. Our imputation strategy would anticipate the $t+2$ high price to $t+1$, when newborns do not change. In this case we should find that future changes in newborns may affect current prices. When we regress lead values of newborns on current prices we find no effect. This is reassuring on the fact that our imputation strategy is not biasing our results in a relevant way.
} 
pharmacy $i$ in basket $g$ and month $t$ are defined by:

$$
\begin{aligned}
p_{i g t} & =\frac{\sum_{k=1}^{K_{g}} p_{i k g t} \bar{q}_{k g}}{\sum_{k=1}^{K_{g}} \bar{p}_{k g} \bar{q}_{k g}} \\
q_{i g t} & =\frac{\sum_{k=1}^{K_{g}} \bar{p}_{k g} q_{i k g t}}{\sum_{k=1}^{K_{g}} \bar{p}_{k g} \bar{q}_{k g}}
\end{aligned}
$$

where $\bar{q}_{k g}$ and $\bar{p}_{k g}$ are the quantity and the price for product $k$ of basket $g$, respectively sold and charged on average by all pharmacies in all months. In other words, $p_{i g t}$ is the weighted average price charged by pharmacy $i$ in month $t$ for the entire basket $g$, where the weights are based on the quantities of each item of the basket sold on average in the entire market over all months. So, for each basket, this price index is independent of the quantities sold by pharmacy $i$ and changes over time (and with respect to any other pharmacy $f$ ) if and only if the price of at least one item changes in pharmacy $i$ (or $f$ ). In particular, it is important to note that if a change in the composition of the population induces the pharmacists to sell a relatively more expensive product $k^{\prime}$ instead of a less expensive one $k$ (because, for example, parents of newborns are more exigent consumers and prefer a more expensive brand $\left.k^{\prime}\right)$, this substitution would leave the price index $p_{\text {igt }}$ unaffected, as long as the pharmacists keep the prices of the two products unchanged. In this example, it is only when $p_{i k g t}$ and $p_{i k^{\prime} g t}$ change over time that we can observe a variation in the price index.

Similarly, the quantity index $q_{\text {igt }}$ is the weighted average quantity sold by pharmacy $i$ in month $t$ for the entire basket $g$, where the weights are based on the prices of each item charged on average in the entire market over all months. So also this quantity index is independent of the prices charged by pharmacy $i$ and changes over time (and with respect to any other pharmacy $f$ ) if and only if the quantity of at least one item in basket $g$ changes in pharmacy $i$ (or $f$ ).

As explained above, since newborns are measured at the city level, the price and quantity indexes $p_{i g t}$ and $q_{i g t}$, constructed for each basket $g$ of products observed at time $t$ in pharmacy $i$, have to be averaged over the pharmacies in each city $c$, thus finally obtaining a price $p_{c g t}$ and a quantity $q_{c g t}$ observed in city $c$ for basket $g$ at time $t$.

The temporal evolutions of the price and quantity indexes (averaged over cities) for the 
three baskets of products $g=\{$ Hygiene, Diaper, Milk $\}$ in the pharmacies of the Pharma dataset, are plotted in the left panels of Figures 2 and 3. Our empirical strategy exploits the within city and across time variability of these variables. The right panels of the same figures plot the residuals of regressions of each (log) price and (log) quantity on city fixed effects. These residuals show that, for each basket, both the quantity and the price change substantially over time at the city level.

We are also interested in the effects of changes in the degree of competition between sellers for the market under study (see Remark 2). To study these effects we need an exogenous source of variation in the number of pharmacies, which is offered by the rules that regulate the Italian pharmacy market. In Italy, entry in and exit from this market are determined by the Law 475/1968 that establishes (as in many other countries) the so-called "demographic criterion" to define the number of pharmacies authorised to operate in each city. Specifically, the law states a set of population thresholds at which the number of existing pharmacies that should operate in a city changes discontinuously. Leaving the details to Section 5 , here we just mention that, for our purposes, this law generates a Regression Discontinuity design that allows for the possibility to estimate the causal effect of a change in the number of competing pharmacies at each threshold.

\section{Effects of changes in the proportion of inelastic con- sumers in a market}

We use the data described in the previous Section to first estimate the parameters of the following linear regression, which allows us to test the predictions of the theory by comparing the elasticities of prices to newborns for a basket of products demanded by heterogeneous consumers ( $g$ = Hygiene) and a basket of products demanded by homogeneous consumers ( $g=$ Diapers or Milk powders):

$$
p_{c g t}=\delta N_{c t r}^{B}+\lambda N_{c t o}^{B}+\delta^{D} N_{c t r}^{B} D_{g}+\lambda^{D} N_{c t o}^{B} D_{g}+\psi_{c g}+\mu_{t}+\varepsilon_{c g t}
$$


where $D_{g}=1$ if $g=$ diapers (or milk powders), $c \in\{1, \ldots, C\}$ denotes cities, $t \in\{1, \ldots, T\}$ denotes months, $r$ (for recent) denotes the 12 months that include and precede $t$ and $o$ (for older) denotes the 12 months that include and precede $t-12 . p_{\text {cgt }}$ is the (log) price index charged by the $S_{c}$ pharmacies in city $c$ during month $t$ for product $g . N_{c t r}^{B}$ is the log of the total number of babies that are born in city $c$ during the 12 months that include and precede $t$ (recent newborns) and who are potential buyers of product $g$ in month $t$. Similarly, $N_{c t o}^{B}$ is the log of the total number of babies that are born in city $c$ during the 12 months that include and precede $t-12$ (older newborns) and who are as well potential buyers of product $g$ in month $t . \psi_{c g}$ are city $\times$ product fixed-effects which capture relevant characteristics of city markets, among which, most importantly, the number of pharmacies in each city that is time invariant in our sample. $\mu_{t}$ are time fixed effects that capture relevant characteristics of calendar months, like seasonal effects.

Our identifying assumption requires that, for the case of hygiene products, the city $\times$ product and time fixed effects capture, up to a random component, the number of other consumers $N_{c t}^{A}$, for the part of this number that is independent of newborn parents. But the stock of other consumers may change also because parents, with the passage of time from delivery, become similar to other adults and ultimately join the stock itself. This is captured by the differentiation between $N_{c t r}^{B}$ and $N_{c t o}^{B}{ }^{15}$ Finally, $\varepsilon_{c g t}$ is an error term, which is allowed to display heteroskedasticity and serial correlation at the city level. This, however, is not a threat for our identification strategy, since it does not affect the randomness, at the monthly frequency and controlling for city $\times$ products fixed effects, of the numbers of recent $N_{c t r}^{B}$ and older $N_{\text {cto }}^{B}$ newborns.

In equation (6), $\delta$ measures the elasticity of the price of hygiene products with respect to recent newborns while $\delta^{D}$ measures by how much this elasticity differs from the equivalent one of diapers or milk powders. Similarly for $\lambda$ and $\lambda^{D}$ in reference to older newborns. Table 2 reports the elasticities estimated for hygiene and diapers (or milk powder) and their difference based on equation (6), with standard errors that are robust to heteroskedasticity and serial correlation at the city level. All (log) variables have been standardized, dividing

\footnotetext{
${ }^{15}$ Estimates that disaggregate the effects of newborns in each month are reported in Tables A.2.2 - A.2.7 of the Appendix for online publication. Table A.2.8 of the same Appendix presents instead estimates that control for city specific or product specific time trends, and conclusions are qualitatively unchanged.
} 
them by the their $(\log )$ standard deviation. The descriptive statistics of the variables used in this regression are in Table 1.

In the top panel of the table the entire sample is considered, while, in the bottom panel, estimates are restricted to the sample of cities in which Pharma has full coverage. Starting with hygiene products in the first column, one standard deviation increase in the number of recent newborns raises by almost $30 \%$ of a standard deviation the price of this product. The estimated effect for lagged newborns is slightly smaller but both estimates are statistically significant. As discussed in Section 2, however, these positive and significant estimates are not necessarily evidence of a composition effect induced by the inflow of more rigid newborn parents in the market (see Remark 1), because they could simply result from the scale effect induced by increasing marginal costs, even in the absence of differences between newborn parents and other customers in terms of elasticity.

To test this possibility, the second column of Table 2 focuses on the basket of diapers, which are demanded by newborn parents only, and the third column displays the difference between the effect of newborns on hygiene products and the effect on diapers. Because of Remark 1.1, only if marginal costs are increasing (decreasing) the price of diapers should increase (decrease) when more babies are born. The estimated elasticities for this basket, in the second column, are not significantly different from zero, consistently with non-increasing marginal costs. More importantly, the difference between the elasticities of hygiene products and diapers (respectively $\delta^{D}$ and $\lambda^{D}$ for recent and older newborns), reported in the third column of Table 2, is negative and significant. This difference nets out the scale effect and measures only the extent to which pharmacies are able to use their market power to extract rents from newborn parents when they enter the market. Its negative sign therefore implies that newborn parents are indeed relatively less elastic consumers.

To confirm this conclusion, the last three columns of Table 2 report similar results based on the sub-sample of pharmacies and months for which we have information on both hygiene products and milk powder sales. The fourth column reports estimates of $\delta$ and $\lambda$ for hygiene products in this sub sample, and these are again both positive and significant, although smaller in size than the ones obtained for diapers in the slightly different sample of column 1. In the fifth column, the equivalent estimates for milk powders are not significant (one 
positive and the other negative), as in the case of diapers. Given that also milk powders are demanded only by newborn parents, we have again evidence of an insignificant scale effect which is consistent with non increasing marginal costs. Finally, the differences in the last column of Table 2 provide an alternative estimate of the composition effect described in Remark 1. For recent newborns, the difference is negative but not statistically significant when all cities are considered, while it is negative and strongly significant when the cities with full Pharma coverage are considered. The difference for lagged newborns is always negative and significant. We can therefore again conclude that newborn parents are indeed relatively less elastic consumers from which sellers can extract surplus.

These conclusions rest on the maintained assumption that the marginal costs for hygiene products are similar to those of diapers and milk powders, which, from the estimates in the second and fourth columns of Table 2, appear to be constant or at least not increasing. Although we do not have precise measures of marginal costs, there are good reasons to claim that they are indeed constant or at least not increasing not only for diapers and milk powders but also for hygiene products. In these pharmacies marginal costs may be increasing (for any product) only if one or more of the following three possible conditions holds: (i) if the wholesale contracts with suppliers are characterized by increasing wholesale prices (i.e. quantity premia), (ii) if there are capacity constraints so that shops run the risk of remaining out of stock, and (iii) if it is proportionally more costly to serve more consumers in the shop due to congestion and queuing (having people queuing in the shop may discourage future visits of more profitable consumers).

As for the first possibility, Figure 4 shows that wholesale contracts for pharmacists involve, if anything, quantity discounts which should reflect into decreasing marginal costs. This figure is based on data concerning wholesale price schedules that we obtained from "InfoSystem" (fictitious name for confidentiality reasons), a software house specialized in managing information systems for pharmacies in Italy. The data refer to 9 wholesalers in the province of Milan. ${ }^{16}$ Although this sub-sample is clearly non-randomly selected, since wholesale pharmaceutical contracts are similar across the country according to the information at our disposal, we have no reason to expect that it should give a severely distorted

\footnotetext{
${ }^{16}$ We were not able to access this highly confidential information for a larger sample.
} 
image of the rest of the pharmacies considered in this study, at least as far as wholesale prices are concerned. For each one of the three baskets, the figure plots the marginal costs faced by pharmacies for different numbers of acquired units of each product (i.e. the change in cost for any additional box of product, normalizing to 100 the cost of the first box of diapers purchased). All these lines are similarly downward sloping and, if anything, the one for hygiene products even more than that of diapers and milk powders. This is at least suggestive that the component of marginal costs that depends on wholesale prices is similar and non-increasing.

As for the possibility of shortages of inventories, the Italian law (D.Lgs. 538/92) imposes to wholesalers the responsibility to make sure that pharmacies never incur in shortages of inventories. Indeed, they must supply medicines and other products to each pharmacy independently of their location - as soon as possible and in any event within 12 working hours from the request. Moreover, the wholesalers must ensure the availability of all the medicines listed by the Board of Health and of $90 \%$ of all the items potentially sold by a pharmacy. ${ }^{17}$ Therefore, with a simple phone call, pharmacies can receive supplies of hygiene products, diapers and milk powder more than once a day, at no additional costs and even in small/remote cities. Hence, there is no effective shortage of inventories that might be binding for more than few hours.

Finally, there is the possibility of increasing marginal costs generated by congestion and queuing. If the increase of newborns had the potential to generate a queue of parents in the pharmacy and if expected revenues from them were lower than the ones that could be expected from other consumers (of any product), the pharmacist could react by increasing prices on child hygiene products in order to reduce the undesired queue of parents of newborns. However, in this case we should observe an increase in the price diapers and milk powders too when newborns increase, which is clearly not the case, as shown in Table 2. Moreover, this possibility is extremely unlikely in our environment because child hygiene products represent, on average, a tiny percentage of the monthly transactions of a pharmacy. $^{18}$

\footnotetext{
${ }^{17}$ For further details on the obligations of wholesalers towards pharmacies in Italy, see again AGCM (1997).

${ }^{18}$ Evidence from till receipts issued by the pharmacies in our sample shows that those containing at least one child hygiene product are, on average, less than $2.2 \%$ of all monthly till receipts (i.e. around 130 over a
} 
To sum up, using the effects of newborns on the prices of diapers and milk powders as an estimate of the scale effect associated with possibly non-constant marginal costs, we have been able to identify the part of the effect of newborns on the price of hygiene products that can be confidently considered a composition effect, i.e. the price increase that measures the capacity of pharmacies to extract surplus from the inflows of more rigid newborn parents in the market.

In the next section we explore the extent to which this capacity is reduced when market power declines because of an exogenous increase in the number of sellers.

\section{Can competition limit the capacity of pharmacies to extract surplus from inelastic consumers?}

As previously anticipated, entry and exit in the pharmacy market is regulated in Italy by law 475/1968 which establishes how many pharmacies should operate in a city as a function of the existing population. Below 7500 inhabitants there should be only one pharmacy, while from 7500 to 12500 there should be two pharmacies; above this threshold a new pharmacy should be added every 4000 inhabitants. Compliance with this theoretical rule is however imperfect for at least two reasons. First, cities that are composed by differentiated and land locked geographical areas with difficult transport connections (e.g. because of mountain ridges or rivers), are allowed to have more pharmacies than what would be implied by the demographic rule. Second, the evidence suggests that it is easier to open a pharmacy than to close one, probably because of the difficulty of "deciding" who should exit the market when pharmacies are too many (the law being silent on this issue). In some rare occasions market forces induce the bankruptcy of the weakest pharmacy in a city in which demand is no longer sufficient to sustain positive profits for all the existing ones. But otherwise, the evidence suggests that, given the rents that a pharmacy probably grants to its owners in a highly regulated market, new sellers enter immediately whenever possible, but very few later exit if and when the city population declines.

total monthly average of 5,800). A $100 \%$ increase in monthly sales of child hygiene products would thus yield an increase of around $2.2 \%$ of total demand, which would not be enough to generate substantial queuing in the pharmacy. 
This historical asymmetry in the likelihood that pharmacies are opened or closed generates, nevertheless, an exogenous source of variation in the current number of pharmacies based not on the current population but on the population peak reached since $1971 .{ }^{19}$ Consider the threshold of 7,500 inhabitants at which the number of existing pharmacies should theoretically increase from 1 to 2, according to the law. The left panel of Figure 5 shows local polynomial smoothing (LPS) regression estimates of the number of pharmacies as a function of the current city population, together with the $95 \%$ confidence intervals. ${ }^{20}$ No discontinuity in the number of competitors can be appreciated. The right panel of the same Figure shows instead analogous LPS regression estimates of the number of pharmacies against the maximum level reached by the city population since 1971. Here the discontinuity is large and statistically significant.

As far as imperfect compliance is concerned, the figure also shows that there are indeed cities in which the population never went above 7500 units since 1971 and nevertheless have more than one pharmacy for the already mentioned historical or geographic reasons. Similarly, on the right of the threshold, the average number of pharmacies is larger than two, more than what the law would prescribe. But even in the presence of this generalized "upward non-compliance", a significant discontinuity of approximately half a pharmacy emerges at the threshold. At higher thresholds, involving larger cities with more pharmacies, also the compliance with the rule based on the historical population peak is more blurred, so that we are forced to use only the first threshold of 7500 units for our analysis. This however is enough to test in a clean way the theoretical predictions concerning the effects of competition in these markets (Remark 2). ${ }^{21}$

To measure precisely the strength and significance of the discontinuity in the number of pharmacies at the first threshold, we estimate jointly two polynomials of the number of pharmacies as functions of the distance of city population from the threshold, one for each side of the threshold. The difference in the values of the two polynomials at the threshold (i.e.

\footnotetext{
${ }^{19}$ The 1971 Census is the first reliable population measure at the city level after the date of enactment of Law 475/1968.

${ }^{20}$ For municipalities in which pharmacies are observed in our dataset since January 2007, current population is measured at December 31, 2006; for municipalities in which pharmacies are observed since January 2009, current population is measured at December 31, 2008.

${ }^{21}$ It would instead not be enough for a complete policy design since we only have insights concerning changes from approximately 1 to approximately 2 pharmacies in relatively small cities.
} 
the coefficients of order zero of the two polynomials) measures the size of the discontinuity. Specifically, let $\kappa=7500$ denote the first threshold set by the Law. Define $K_{c}=1\left(\operatorname{Pop}_{c} \geq \kappa\right)$ to be a a dummy taking value 1 for city $c$ on the right hand side of the $\kappa$-threshold, and the vectors $V_{c}$ and $\rho$ as

$$
V_{c}=\left(\begin{array}{c}
\left(1-K_{c}\right) \cdot f\left(\operatorname{Pop}_{c}-\kappa\right) \\
K_{c} \cdot f\left(\operatorname{Pop}_{c}-\kappa\right)
\end{array}\right) \quad \rho=\left(\begin{array}{c}
\rho_{\mathbf{l}} \\
\rho_{\mathbf{h}}
\end{array}\right)
$$

where $\operatorname{Pop}_{c}$ is the maximum historical population in a city; $f\left(\operatorname{Pop}_{c}-\kappa\right)$ denotes the terms of order greater than zero of the polynomials in $\left(\mathrm{Pop}_{c}-\kappa\right)$ on the two sides of the threshold; $\rho_{\mathbf{l}}$ and $\rho_{\mathbf{h}}$ are vectors of the coefficients for each term of order greater than zero of the polynomials, respectively on the low and on the high side of the threshold. Then, the number of pharmacies in a city $S_{c}$ can be estimated using the following equation:

$$
S_{c}=\rho_{\mathbf{l 0}}+V_{c}^{\prime} \rho+\rho_{\mathbf{h} \mathbf{0}} K_{c}+\zeta_{c}
$$

In this equation $\rho_{\mathbf{1 0}}$ is the term of grade zero of the polynomial in $\left(\mathrm{Pop}_{c}-\kappa\right)$ on the low side of the threshold and measures the expected number of pharmacies immediately below the threshold:

$$
\rho_{\mathbf{1 0}}=\lim _{\operatorname{Pop} \uparrow \kappa_{\kappa}} E\left(S_{c} \mid \operatorname{Pop}_{c}=\kappa\right)
$$

The parameter $\rho_{\mathbf{h} \mathbf{0}}$ measures instead the difference between the number of pharmacies immediately above and below the threshold, so that:

$$
\rho_{\mathbf{h} \mathbf{0}}=\lim _{\operatorname{Pop} \downarrow \kappa} E\left(S_{c} \mid \operatorname{Pop}_{c}=\kappa\right)-\lim _{\operatorname{Pop} \uparrow \kappa} E\left(S_{c} \mid \operatorname{Pop}_{c}=\kappa\right)
$$

Panel A in Table 3 reports estimates of equation (8) with polynomials of different degrees (from 1st to 4th) and with windows of different size around the threshold $( \pm 2000$ and $\pm 3,000$ inhabitants). Independently of the specification, these estimates confirm the visual impression of Figure 5, suggesting an even larger discontinuity at the threshold: from half a pharmacy in column 1 to more than three fourth of a pharmacy in column 3. Panel B of the same Table probes these results in other ways. Column 1 reports the mean difference in the 
number of pharmacies belonging to cities that are within a window of plus or minus 1000 inhabitants from the threshold. Column 2 estimates equation (8) on the restricted sample of cities in which Pharma has a $100 \%$ coverage. ${ }^{22}$ Column 3 includes, in the unrestricted specification of equation (8), observable controls that, as we will see, are balanced around the threshold but may improve efficiency in the estimation. ${ }^{23}$ Finally, column 4 reports estimates based on a local linear regression with bandwidth equal to 2000. Also in Panel B the estimates of the discontinuity at the threshold range between half a pharmacy and three fourth of a pharmacy.

Having shown that the number of pharmacies effectively changes discontinuously at the first threshold, we now have to provide evidence supporting the identifying assumption for a Regression Discontinuity (RD) design, requiring that nothing else which might be relevant changes discontinuously at the same threshold. Figure 6 shows the LPS regressions of six observable "pre-treatment" factors on the maximum historical population since 1971: the number of wholesalers serving the pharmacies in the city; the number of other shops in the city, like supermarkets, possibly selling some hygiene products, diapers and milk powders; the average monthly number of newborns; a dummy taking value 1 if the city is in a urban area; a dummy taking value 1 if the city is in Northern Italy and per capita disposable income (measured in 2008) at the city level. For none of these variables a quantitatively or statistically significant discontinuity should be observed at the threshold and this is precisely the evidence emerging from the figure. ${ }^{24}$ Moreover, note that we are not aware of any other law setting entry thresholds for other industries in a neighbourhood of 7,500 inhabitants nor we know of any other regulation referring to the same threshold, so that the effect that we

\footnotetext{
${ }^{22}$ Here the polynomial is of third degree and the window is plus or minus 2500 inhabitants.

${ }^{23}$ In this specification the polynomial is of third degree and the window is plus or minus 3000 inhabitants. The included controls are: the average monthly number of newborns, a dummy taking value 1 if the city is in a urban area, a dummy taking value 1 if the city is in Northern Italy, and per capita disposable income at the city level.

24 Nonetheless, in some empirical specifications we include these variables as regressors to increase efficiency. We have also tested the existence of a discontinuity at the threshold for these variables using local linear and polynomial regressions for different windows around the threshold (as suggested by Imbens and Lemieux (2008)). Results uniformly fail to identify any significant discontinuity. Additional covariates for which the continuity hypothesis has been tested include the population growth rate since 1971, per capita consumption, per capita expenditure on pharmaceuticals, the number of convenience-stores allowed to sell drugs ('parafarmacie'), and the number of grocery stores, all at the city level. The expected values of all these variables do not show any significant discontinuity at the threshold. Results are available upon request.
} 
are going to estimate can be ascribed solely to law 475/1968.

Another crucial assumption for the validity of a fuzzy RD approach is that the assignment rule has a monotone effect on the treatment variable (see Imbens and Lemieux (2008)). We provide evidence in favor of monotonicity with the test developed by Angrist, Graddy, and Imbens (2000). Figure 7 plots the cumulative distribution function of the number of pharmacies (our treatment variable) for the two groups defined by our instrumental variable (i.e., those below and above the 7500 inhabitants threshold). The plot shows that the CDF above the threshold stochastically dominates the one below the threshold, as it must happen if monotonicity holds. ${ }^{25}$

Since the conditions for a $\mathrm{RD}$ design are satisfied we can now describe what we learn from estimates based on such design, concerning the effect of competition on the ability of firms to extract surplus from inelastic consumers. To this end, we test, for each of the three baskets (hygiene products, diapers and milk powders), whether the composition effect on prices of an increase in the number of inelastic consumers (newborn parents) is different on the two sides of the threshold $\kappa=7500$, where the levels of competition between pharmacies changes while everything else is equal.

Figures 8 plots the LPS regression estimates of the elasticity of price with respect to the number of newborns on the two sides of the threshold for each of the three products. In the case of hygiene the discontinuity at the threshold is sizeable: below the threshold, where the number of competing pharmacies is lower, the composition effect is positive, while above it is not different from zero. In line with theoretical predictions, we therefore see that for a product demanded by heterogenous consumers the elasticity of price to newborns reduces when competition increases, suggesting that pharmacies facing higher competition are less able to extract surplus from inelastic consumers. For diapers and milk powders, instead, there is no evident discontinuity in the estimates of the elasticity. In the case of these products, which are demanded by an homogenous group of consumers, there is no composition effect independently of the level of competition on the two sides of the thresholds.

\footnotetext{
${ }^{25}$ We tested also for manipulation of the running variable around the threshold using the McCrary (2008) density test. It seems unlikely that our running variable (the maximum population reached by the city between 1971 and 2008) could have been manipulated by pharmacies, and indeed the test confirms this hypothesis $(\mathrm{p}$-value $=0.31)$.
} 
To measure precisely the discontinuity of the composition effect at the $\kappa=7500$ threshold, we test whether there is a jump at this threshold in the difference between the price elasticities of hygiene products and diapers with respect to newborns. ${ }^{26}$ As already explained, this difference measures the composition effect net of any scale effect. For this purpose, we model the $(\log )$ price as a function of the (log) numbers of recent and old newborns, fully interacted with different polynomials in the distance of the city population from the threshold, one for each side of the threshold and for each product. The specification includes also city $\times$ product fixed and month fixed effects. The idea of this strategy is that, on the two sides of the thresholds and for each product, the elasticity of price to newborns may change continuously for various reasons, as a function of city population, and the different polynomials capture this variation. However, no discontinuity should be observed at the threshold for the elasticity of a product unless the exogenous change in the number of sellers at the threshold has an effect. The coefficients of the interactions of newborns with the terms of order zero of the polynomials measure the elasticities of price to newborns for each product immediately above and below the threshold. If these coefficients differ for a given product, it means that the elasticity of that product is discontinuous at the threshold.

Specifically, we estimate the following joint model of the effect of newborns on prices for the two products on the two sides of the threshold:

$$
\begin{aligned}
p_{c t g} & =\theta N_{c t r}^{B}+\xi N_{c t o}^{B} \\
& +\theta^{D} N_{c t r}^{B} D_{g}+\xi^{D} N_{c t o}^{B} D_{g} \\
& +\theta^{K} N_{c t r}^{B} K_{c}+\xi^{K} N_{c t o}^{B} K_{c} \\
& +\theta^{D K} N_{c t r}^{B} D_{g} K_{c}+\xi^{G K} N_{c t o}^{B} D_{g} K_{c} \\
& +N_{c t r}^{B} V_{c}^{\prime} \varphi+N_{c, t, o}^{B} V_{c}^{\prime} \phi \\
& +D_{g} N_{c t r}^{B} V_{c}^{\prime} \varphi^{D}+D_{g} N_{c t o}^{B} V_{c}^{\prime} \phi^{D} \\
& +\chi_{c g}+\eta_{t}+u_{c g t}
\end{aligned}
$$

where the last line contains the city $\times$ product and month fixed effects as well as the error

\footnotetext{
${ }^{26}$ We follow Grembi, Nannicini, and Troiano (2014) in calling this type of analysis a Difference-inDiscontinuities approach.
} 
term. The previous two lines contain the interactions between recent and old newborns and the terms of order greater than zero of the polynomials on the two sides of the threshold for each of the two products ( $V_{c}$ is defined as in equation (7) and the $\varphi$ and $\phi$ parameters play the same role as $\rho$ in the same equation).

In equation (9) the main coefficients of interest are $\theta, \theta^{D}, \theta^{K}$ and $\theta^{D K}$, attached to the interactions of the number of recent newborns with the terms of zero order of the polynomials. The first of these coefficients, $\theta$, is the elasticity of the price of hygiene products to the number or recent newborns immediately below the threshold, where only one pharmacy should operate according to the law and market power is high. The other coefficients measure by how much the other elasticities differ respectively for diapers immediately below the threshold $\left(\theta^{D}\right)$, for hygiene immediately above the threshold $\left(\theta^{K}\right)$ and for diapers immediately above the threshold $\left(\theta^{D K}\right)$. Similarly for the $\xi$ parameters concerning the elasticities with respect to older newborns.

Estimates of the elasticities of prices with respect to recent newborns, for the comparison of hygiene products versus diapers, are reported in Table 4. In the first column of the top panel, the polynomial $f\left(\operatorname{Pop}_{c}-\kappa\right)$ is of first order and the window around the population threshold is \pm 2000 units. The first row reports the elasticity of the standardized price of hygiene products with respect to the standardized number of recent newborns immediately below the threshold (the parameter $\theta$ in equation (9)). This elasticity is estimated to be slightly larger than 1 and to be strongly statistically significant. The second row estimates how the analogous elasticity for diapers deviates from the elasticity for hygiene below the threshold (the parameter $\theta^{D}$ ). The point estimate of this difference is negative and large enough in absolute size to indicate that the elasticity for diapers immediately below the threshold is essentially null. The third row indicates that the elasticity for hygiene products drops significantly above the threshold becoming not distinguishable from zero (the parameter $\theta^{K}$ ). This result explains why the estimate of $\theta$ in equation (9) is almost three times as large as the estimate of $\delta$ in equation (6), reported in Table 2. While here the elasticity $\theta$ is estimated only on cities below the threshold, the elasticity $\delta$ in equation (6) is estimated on all cities, including those above the threshold in which, we now know, the composition effect is null. Finally, the fourth row shows that, for diapers, the elasticity 
remains indistinguishable from zero also above the threshold (the parameter $\theta^{D K}$ ).

To sum up, these estimates are in line with the theoretical predictions and replicate the graphic evidence of the top two panels of Figure 8. For hygiene products, that are demanded by heterogeneous consumers, the elasticity to newborns (which, given constant marginal costs, measures the composition effect) is definitely positive below the threshold where competition is low and equal to zero above the threshold where competition is high. For diapers, instead, that are demanded by homogeneous consumers, the elasticity is not different from zero on both sides of the threshold and no discontinuity emerges. The evidence for diapers is indeed consistent with non-increasing marginal costs and, therefore, the positive elasticity on the high side of the threshold for hygiene is entirely driven by the composition effect.

The other estimates of Table 4 show that these conclusions are robust to the use of different windows around the threshold (top panel: $\pm 2000, \pm 2500, \pm 3000$, with a polynomial of first order); the use of different polynomials (middle panel: 2nd, 3rd and 4th order, with a window of \pm 2500 ); the choice of a local linear bandwidth equal to 2000 (first column of the bottom panel); the restriction to cities with 100\% Pharma coverage (second column of the bottom panel); the inclusion of controls (third column of the bottom panel). ${ }^{27}$ In these different specifications point estimates and significance levels change slightly from those of the first column in the top panel, but are qualitatively similar and support the same conclusions, in line with the predictions described in Remark 2.

To further sustain the robustness of our results, in Table 5 we replicate the same estimation exercise, based on equation (9), comparing hygiene products with milk powders in the slightly different sub sample of pharmacies that sell both these products. ${ }^{28}$ Results are again qualitatively similar to the graphical evidence of Figure 8, in this case with reference to the top and bottom panels. In all the specifications, although with differences in size and precision, the estimated elasticities for hygiene and milk powders differ substantially below the threshold, with the former being positive and statistically significant, while on the other

\footnotetext{
${ }^{27}$ The included controls are: the average monthly number of newborns, a dummy taking value 1 if the city is in a urban area, a dummy taking value 1 if the city is in Northern Italy, and per capita disposable income at the city level.

${ }^{28}$ As already mentioned, milk powders are not sold by pharmacies in some cities, possibly because of breast-feeding preferences.
} 
side of the threshold they are both indistinguishable from zero.

Finally, equation (9) performs the same Difference-in-Discontinuities exercise for the effects of older newborns on prices that, as already anticipated, we keep separate to allow for the possibility that newborn parents become more similar to other adult consumers with the passage of time from birth. Not surprisingly, results for this comparison, which are reported in Tables A.2.9 and A.2.10 of the Appendix for online publication, are qualitatively similar but less statistically significant, particularly for the subsample in which we compare hygiene products to milk powders.

\section{Conclusions}

In this paper we provide new evidence on the role of consumers' heterogeneity, in terms of price elasticity, for the retail sector and on its interplay with competition among sellers. Theory predicts that an inflow of less experienced consumers with higher search costs should have a positive effect on the average price charged by sellers. This composition effect (generated by sellers being able to extract larger rents from inelastic consumers through higher prices) should also decline as the number of competitors increases. However, it maybe difficult to identify empirically this composition effect because it may be confounded by a scale effect if marginal costs faced by sellers are non-constant.

We gather data for a large sample of Italian pharmacies and estimate the effect of a positive shock in the number of newborns (at the monthly frequency and controlling for city and time fixed effects) on the average price at the city level for a basket of child hygiene products (demanded by newborns' parents and other consumers) and for diapers and milk powders (demanded by newborns' parents only). We argue that parents of newborns indeed face higher search costs because they are more hurried and are also less experienced than other consumers of the same set of products. Thus, an increase of newborns is a source of exogenous variation in the number of relatively inelastic consumers. Consistently with theoretical predictions, an increase in newborns has a positive effect on the average observed price of hygiene products which is significantly larger than that on the prices of diapers and milk powders which is actually nil, suggesting that marginal costs are constant or at least 
not increasing. This differential impact of the number of newborns on the price of these different groups of products allows us to neatly identify the composition effect, net of any scale effects that may be generated by non-constant marginal costs.

To study the role of competition on the composition effect, we exploit a regulation of entry and exit in the Italian pharmacy market that is common to other countries and is based on a demographic criterion. In Italy the law imposes that municipalities under 7,500 inhabitants should have a single pharmacy, while those right above this threshold should have two. Despite the presence of partial non-compliance with this prescription, we are able to exploit it within a Regression Discontinuity design and show that the elasticity of prices of hygiene products to the number of newborns declines to zero in cities where the number of pharmacies is higher because population is above the threshold. No discontinuity is instead observed, as expected, for the elasticities of diapers and milk products. These results confirm the theoretical prediction that competition reduces the capacity of firms to extract surplus from less elastic buyers. 


\section{References}

AGCM, Autorità Garante per la Concorrenza e il Mercato. 1997. "Indagine conoscitiva nel settore farmaceutico del 6 novembre 1997." Available (in Italian) at http://tinyurl.com/ccxb4o8.

Aguiar, M. and E. Hurst. 2007. "Life-cycle prices and production." The American Economic Review 97 (5):1533-1559.

Angrist, J., K. Graddy, and G. Imbens. 2000. "Instrumental variables estimators in simultaneous equations models with an application to the demand for fish." Review of Economic Studies 67:499-527.

Brown, J. and A. Goolsbee. 2002. "Does the internet make markets more competitive? Evidence from life insurance industry." Journal of Political Economy CX:481-507.

Graddy, K. 1995. "Testing for Imperfect Competition at the Fulton Fish Market." RAND Journal of Economics 26:75-92.

Grembi, V., T. Nannicini, and U. Troiano. 2014. "Policy responses to fiscal restraints: a difference-in-discontinuities design."

Hortacsu, A. and C. Syverson. 2004. "Product differentiation, search costs, and competition in the mutual fund industry: a case study of S\&P 500 Index funds." Quartely Journal of Economics 119 (2):403-456.

Imbens, G. and T. Lemieux. 2008. "Regression discontinuity design: a guide to practice." Journal of Econometrics 142 (2):615-635.

Lach, S. 2007. "Immigration and prices." Journal of Political Economy 115 (4):548-587.

McCrary, J. 2008. "Manipulation of the running variable in the regression discontinuity design: a density test." Journal of Econometrics 142 (2):698-714.

Sorensen, A. 2000. "Equilibrium Price Dispersion in Retail Markets for Prescription Drugs." Journal of Political Economy 108:833-850. 
Figure 1: Temporal evolution and within city variability of the number of newborns
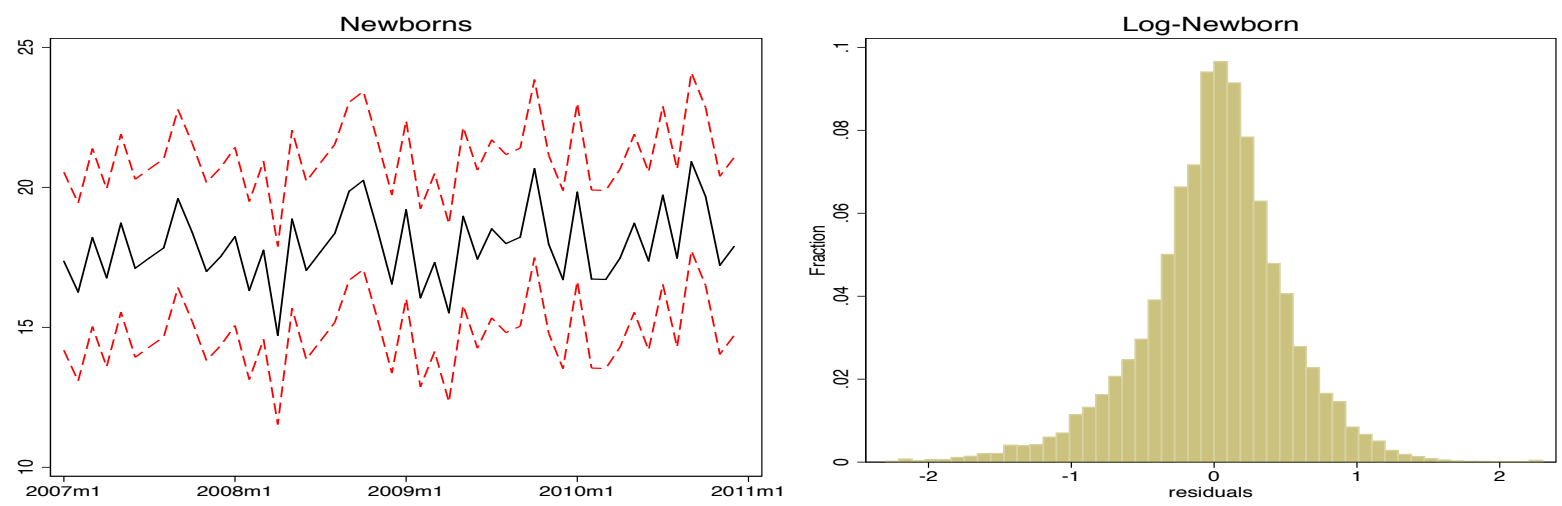

Notes: Temporal evolution of the average number of newborns per city (left panel), and histograms of the residuals of a regression of log-newborns on city fixed effects (right panel). Dashed lines delimit the $95 \%$ confidence interval.

Table 1: Descriptive statistics of the variables used in the econometric analysis

\begin{tabular}{|c|c|c|c|c|}
\hline Mean & $\begin{array}{l}\text { Standard } \\
\text { Deviation }\end{array}$ & Min & Max & $\begin{array}{l}\text { No.of } \\
\text { Obs. }\end{array}$ \\
\hline
\end{tabular}

\section{Hygiene products}

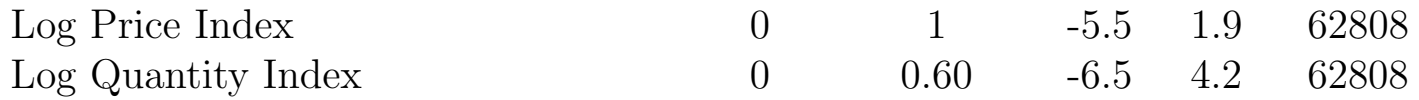

\section{Diapers}

Log Price Index

Log Quantity Index
0

$0 \quad 1.07$

$\begin{array}{ll}-6.9 & 24.7\end{array}$

$-5.1 \quad 5.0$

62808

62808

\section{Milk powders}

Log Price Index

Log Quantity Index

Log Newborns between $t$ and t-12

Log Newborns between t-13 and t-24

No. of pharmacies per city

$\begin{array}{ccccc}0 & 1 & -5.6 & 11.4 & 54404 \\ 0 & 1 & -5.4 & 3.6 & 54404 \\ & & & & \\ 4.5 & 1.3 & 1.8 & 10.2 & 125616 \\ 4.4 & 1.3 & 1.8 & 10.2 & 125616 \\ & & & & \\ 7 & 28 & 1 & 709 & 125616\end{array}$

Notes: Price and quantity information concerning 3039 hygiene products, 2007 types of diaper and 427 types of milk powder sold by the 3331 pharmacies in the Pharma dataset. Note that by construction (see equations (4) and (5) in the text), the price and quantity indexes have mean 1 and thus their logs have mean 0 . Information on newborns refers to the 1548 cities in which the pharmacies of the Pharma dataset operate. One observation is a city in a month. The number of observations for milk powder sales is different than the number of observations for hygiene product and diaper sales because in some cities, possibly because of breast-feeding preferences, pharmacies do not sell milk powder. Additional descriptive statistics for the most frequently sold and most highly priced items in each basket are reported in Table A.1 of the Online Appendix. 
Figure 2: Temporal evolution and within city variability of the price indexes of hygiene products, diapers, and milk powders

\section{Hygiene products}
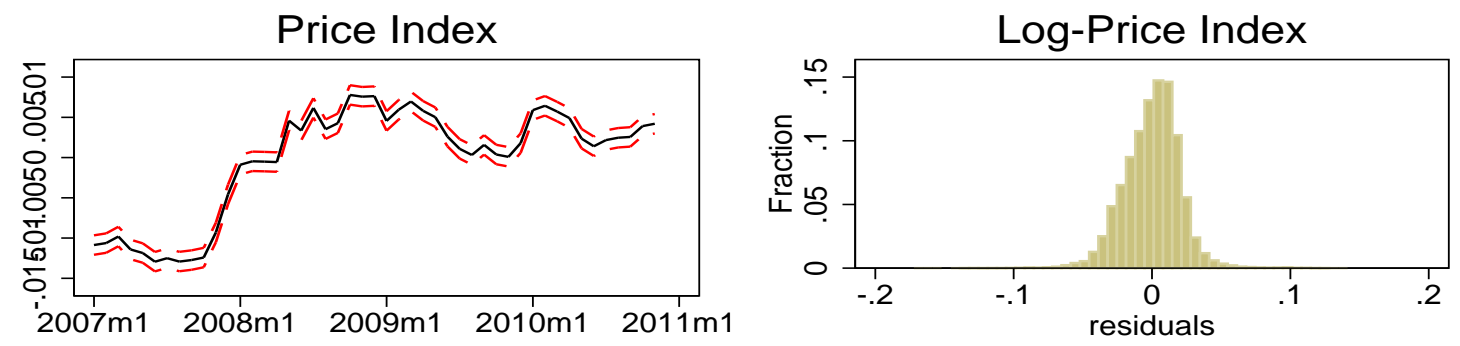

\section{Diapers}
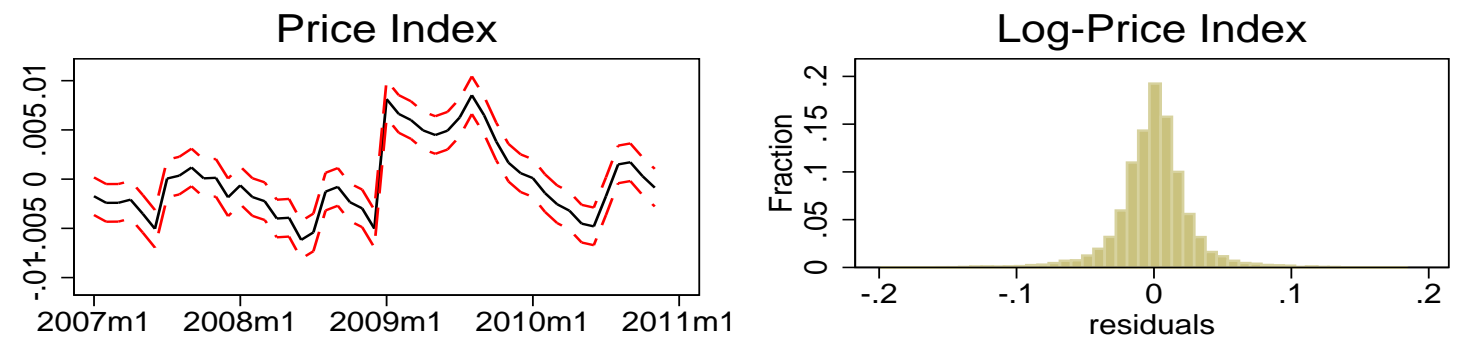

\section{Milk powders}
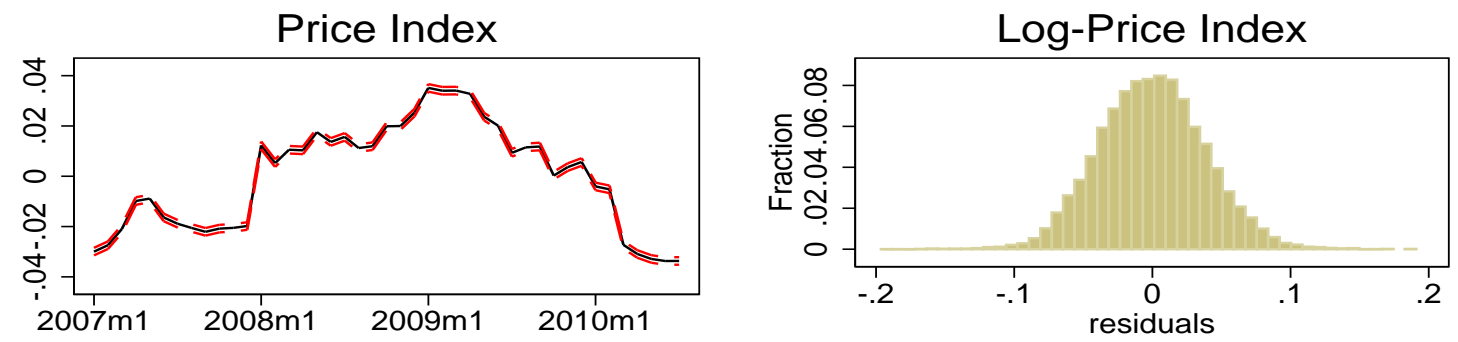

Notes: Temporal evolution of the average price indexes of hygiene products, diapers, and milk powders (left panels), and histograms of the residuals of a regression of the (log) price indexes on city fixed effects (right panels). Dashed lines delimit the $95 \%$ confidence interval. 
Figure 3: Temporal evolution and within city variability of the quantity indexes of hygiene products, diapers, and milk powders

\section{Hygiene products}
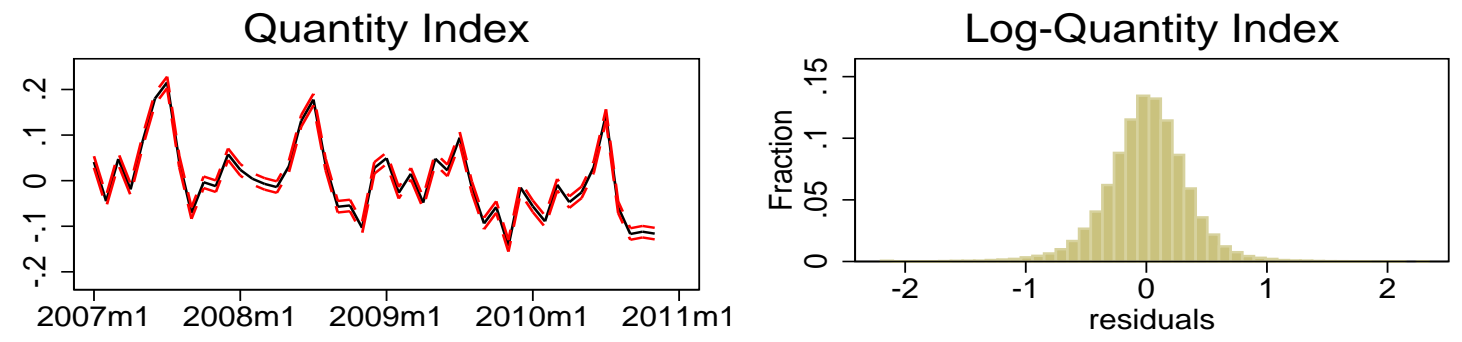

\section{Diapers}
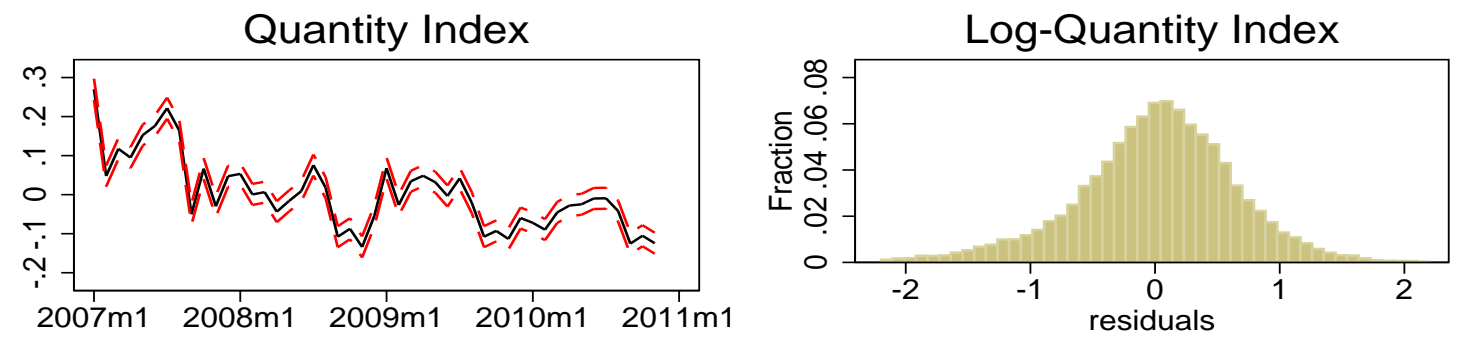

\section{Milk powders}
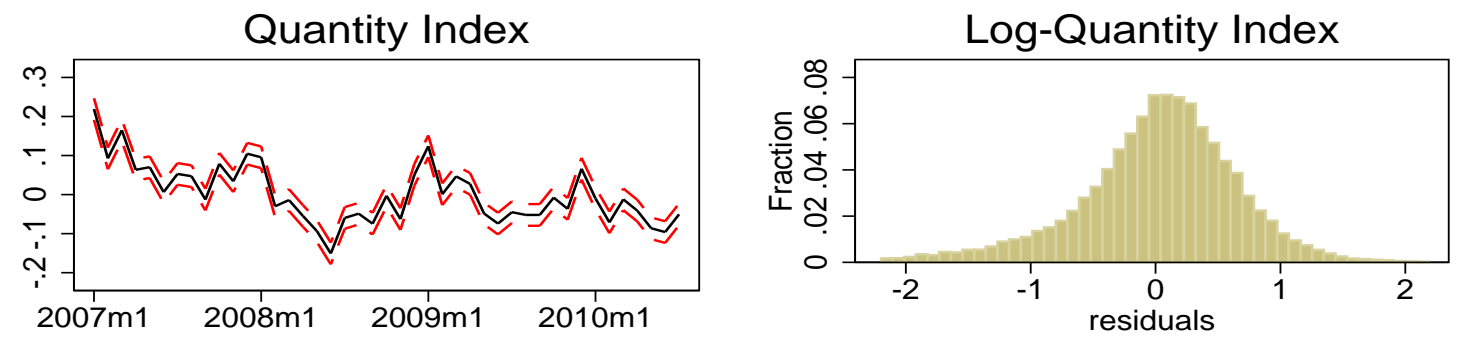

Notes: Temporal evolution of the average quantity indexes of hygiene products, diapers, and milk powders (left panels), and histograms of the residuals of a regression of the (log) quantity indexes on city fixed effects (right panels). Dashed lines delimit the $95 \%$ confidence interval. 
Table 2: Effect of the monthly number of newborns on the equilibrium price

\begin{tabular}{|c|c|c|c|c|c|c|}
\hline & $\begin{array}{l}\text { Hygiene } \\
\qquad \begin{array}{l}(\delta) \\
(\lambda)\end{array}\end{array}$ & $\begin{array}{c}\text { Diaper } \\
\left(\delta+\delta^{D}\right) \\
\left(\lambda+\lambda^{D}\right)\end{array}$ & $\begin{array}{c}\text { Difference } \\
\left(\delta^{D}\right) \\
\left(\lambda^{D}\right)\end{array}$ & $\begin{array}{l}\text { Hygiene } \\
\qquad(\delta) \\
(\lambda)\end{array}$ & $\begin{array}{c}\text { Milk } \\
\left(\delta+\delta^{D}\right) \\
\left(\lambda+\lambda^{D}\right)\end{array}$ & $\begin{array}{c}\text { Difference } \\
\left(\delta^{D}\right) \\
\left(\lambda^{D}\right)\end{array}$ \\
\hline \multicolumn{7}{|l|}{ Panel A: All cities } \\
\hline \multirow[t]{2}{*}{ Log Newborns (t,t-11) } & 0.288 & 0.005 & -0.284 & 0.215 & 0.028 & -0.187 \\
\hline & $(0.058) * * *$ & $(0.054)$ & $(0.068)^{* * *}$ & $(0.080)^{* * *}$ & $(0.082)$ & $(0.134$ \\
\hline \multirow[t]{2}{*}{ Log Newborns (t-12,t-23) } & 0.227 & -0.104 & -0.333 & 0.143 & -0.067 & -0.211 \\
\hline & $(0.062)^{* * *}$ & $(0.069)$ & $(0.084)^{* * *}$ & $(0.066)^{* * *}$ & $(0.067)$ & $(0.095)^{* *}$ \\
\hline Time effects & Yes & Yes & Yes & Yes & Yes & Yes \\
\hline City-product effects & Yes & Yes & Yes & Yes & Yes & Yes \\
\hline Number of observations & 125616 & 125616 & 125616 & 110232 & 110232 & 110232 \\
\hline Number of cities & 1548 & 1548 & 1548 & 1548 & 1548 & 1548 \\
\hline \multicolumn{7}{|c|}{ Panel B: $100 \%$ Pharma coverage } \\
\hline \multirow[t]{2}{*}{ Log Newborns (t,t-11) } & 0.232 & -0.022 & -0.255 & 0.242 & -0.123 & -0.370 \\
\hline & $(0.058)^{* * *}$ & $(0.062)$ & $(0.076)^{* * *}$ & $(0.076)^{* * *}$ & $(0.088)$ & $(0.131)^{* * *}$ \\
\hline \multirow[t]{2}{*}{ Log Newborns (t-12,t-23) } & 0.139 & -0.114 & -0.253 & 0.1027 & -0.143 & -0.270 \\
\hline & $(0.063)^{* *}$ & $(0.077)$ & $(0.095)^{* * *}$ & $(0.066)^{*}$ & $(0.085)^{*}$ & $(0.110)^{* * *}$ \\
\hline Time effects & Yes & Yes & Yes & Yes & Yes & Yes \\
\hline City-product effects & Yes & Yes & Yes & Yes & Yes & Yes \\
\hline Number of observations & 51550 & 51550 & 51550 & 45598 & 45598 & 45598 \\
\hline Number of cities & 694 & 694 & 694 & 694 & 694 & 694 \\
\hline
\end{tabular}

Notes: OLS estimates of equation (6):

$$
p_{c g t}=\delta N_{c t r}^{B}+\lambda N_{c t o}^{B}+\delta^{D} N_{c t r}^{B} D_{g}+\lambda^{D} N_{c t o}^{B} D_{g}+\psi_{c g}+\mu_{t}+\varepsilon_{c g t}
$$

where all variables are in logs, $D_{g}=1$ if $g$ = diapers (or milk powders), $c$ denotes cities, $t$ months, $r$ the 12 months that include and precede $t$ and $o$ the 12 months that include and precede $t-12 . p_{c g t}$ is the equilibrium $(\log )$ price index. $N_{c t r}^{B}$ is the log of the total number of babies that are born in city $c$ during the 12 months that include and precede $t$ (recent newborns), $N_{\text {cto }}^{B}$ is the log of the total number of babies that are born in city $c$ during the 12 months that include and precede $t-12$ (older newborns) $\psi_{c g}$ are city $\times$ product fixed-effects, $\mu_{t}$ time fixed effects. Robust standard error, clustered at the city and time level, in parentheses. ${ }^{* * *} \mathrm{p}<0.01,{ }^{* *} \mathrm{p}<0.05,{ }^{*} \mathrm{p}<0.1$. Reported coefficients and standard errors have been standardized by the standard deviation of the correspondent variable. To evaluate the size of the estimates note that a standard deviation is $\approx 1.3$ for the $(\log )$ number of newborns between $t$ and $t-12$ and the $(\log )$ number of newborns between $t-13$ and $t-24,0.03$ for the (log) price of hygiene product, 0.05 for the $(\log )$ price of diaper and 0.05 for the $(\log )$ price of milk powder. 
Figure 4: Average marginal cost of purchasing from wholesalers faced by pharmacies for child hygiene products (solid line), diapers (dashed line) and milk powders (dotted line)

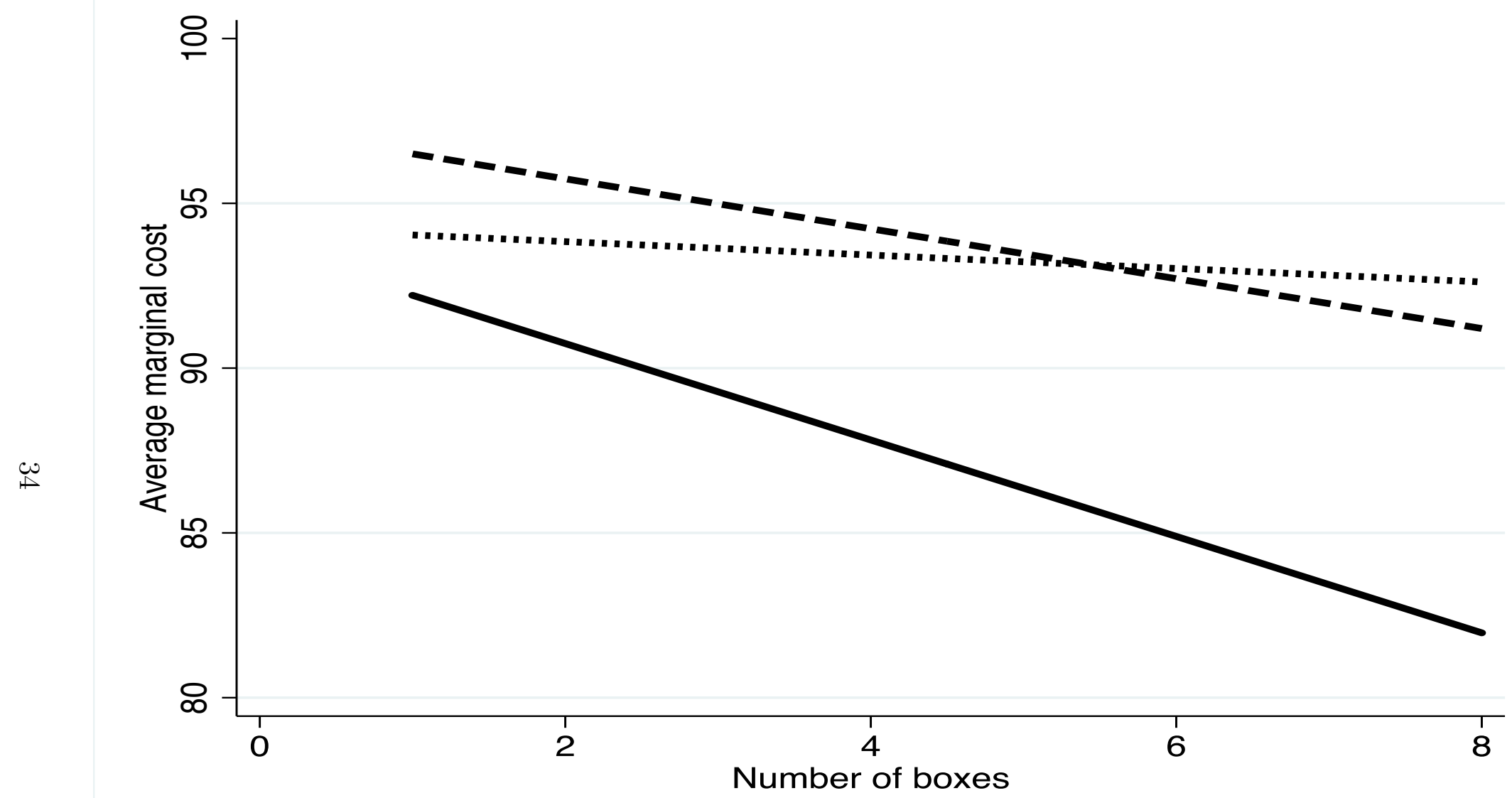

Notes: Linear fit of the marginal costs for different quantities that can be purchased by a pharmacy from 9 wholesalers located in the province of Milan, for each of the three baskets. Marginal costs are obtained from changes in costs for any additional box of product, normalizing to 100 the cost of the first box of diapers and computed as follows. For each product and each quantity that can be purchased by a pharmacist, the wholesale price equals the average price posted by different wholesalers. For each quantity that can be purchased, the wholesale price of the basket is then computed as the weighted average of the wholesale prices of each product, with weights equal to the total quantities actually sold by pharmacies over the period $2007-2010$ 
Figure 5: Current population, maximum population and competition at the threshold
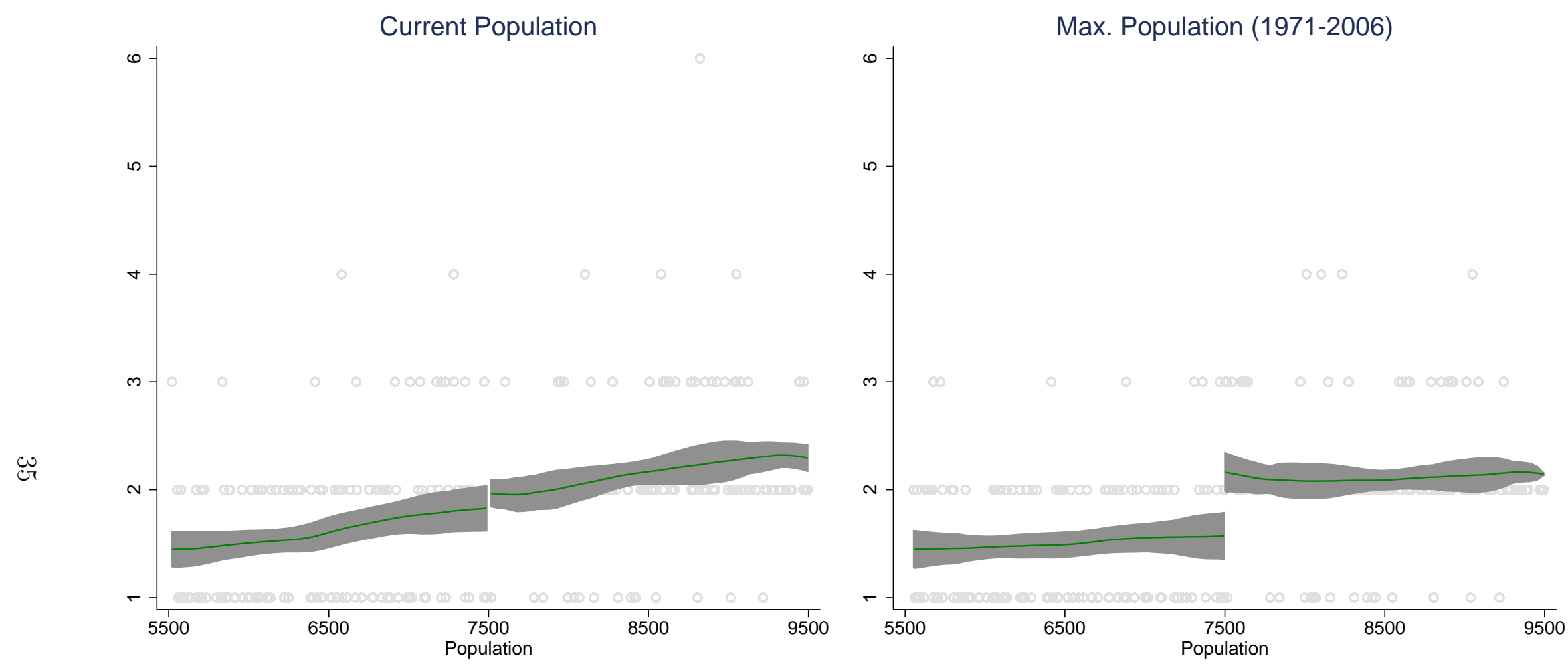

Notes: Scatter plot and local polynomial smoothing regressions (bandwith $=300$ ) of the number of pharmacies with respect to current and maximum historical population Current population is measured at 12-31-2006 for municipalities observed since January 2007, at 12-31-2008 for municipalities observed since January 2009 . 
Table 3: Competing pharmacies on the two sides of the maximum hystorical population threshold.

\begin{tabular}{|c|c|c|c|c|}
\hline \multicolumn{5}{|l|}{ Panel A: Polynomial Results } \\
\hline & $\begin{array}{l}\text { Polynom. } 1^{s t} \\
\pm 2,000 \text { inhabs. }\end{array}$ & $\begin{array}{l}\text { Polynom. } 2^{\text {nd }} \\
\pm 2,000 \text { inhabs. }\end{array}$ & $\begin{array}{l}\text { Polynom. } 3^{\text {rd }} \\
\pm 3,000 \text { inhabs. }\end{array}$ & $\begin{array}{l}\text { Polynom. } 4^{\text {th }} \\
\pm 3,000 \text { inhabs. }\end{array}$ \\
\hline \multirow[t]{2}{*}{ Difference at the threshold $\left(\rho_{h 0}\right)$} & 0.518 & 0.605 & 0.774 & 0.722 \\
\hline & $(0.195)^{* * *}$ & $(0.247)^{* *}$ & $(0.260)^{* * *}$ & $(0.316)^{* *}$ \\
\hline \multirow[t]{2}{*}{ Constant } & 0.619 & 0.644 & 0.584 & 0.609 \\
\hline & $(0.136)^{* * *}$ & $(0.184)^{* * *}$ & $(0.193)^{* * *}$ & $(0.237)^{* *}$ \\
\hline \multirow{3}{*}{$\begin{array}{l}\text { No. of Obs. } \\
\text { Panel B: Additional Results }\end{array}$} & 209 & 269 & 417 & 569 \\
\hline & & & & \\
\hline & $\begin{array}{l}\text { Mean Difference } \\
\pm 1,000 \text { inhabs. }\end{array}$ & $\begin{array}{l}\% \text { Pharma }=100 \\
\pm 2,500 \text { inhabs }\end{array}$ & $\begin{array}{l}\text { With Controls } \\
\pm 3,000 \text { inhabs. }\end{array}$ & $\begin{array}{l}\text { Local Linear Reg. } \\
\text { bandwidth } 2,000\end{array}$ \\
\hline \multirow[t]{2}{*}{ Difference at the threshold $\left(\rho_{h 0}\right)$} & 0.514 & 0.743 & 0.807 & 0.569 \\
\hline & $(0.116)^{* * *}$ & $(0.244)^{* * *}$ & $(0.297)^{* * *}$ & $(0.195)^{* * *}$ \\
\hline \multirow[t]{2}{*}{ Constant } & 0.542 & 0.048 & 0.047 & - \\
\hline & $(0.081)^{* * *}$ & $(0.114)$ & $(0.102)$ & - \\
\hline No. of Obs. & 85 & 109 & 182 & 1548 \\
\hline
\end{tabular}

Notes: OLS estimates of equation (8):

$$
S_{c}=\rho_{\mathbf{1 0}}+V_{c}^{\prime} \rho+\rho_{\mathrm{ho}} K_{c}+\zeta_{c}
$$

where $c$ denotes a city, $S_{c}$ is the number of pharmacies in a city; $V_{c}$ is a vector whose elements are two polynomials (one for each side of the threshold) in the absolute difference between the maximum historical population of the city and the threshold, as defined in equation $(7) ; K_{c}=1\left(P_{o} p_{c}>=\kappa\right)$ is a dummy taking value 1 for cities on the high side of the threshold. Robust standard errors in parentheses. ${ }^{* * *} \mathrm{p}<0.01,{ }^{* *} \mathrm{p}<0.05,{ }^{*} \mathrm{p}<0.1$. Panel A reports results obtained with polynomials of different order. In Panel B column 1 reports the mean difference in the number of pharmacies belonging to cities that are within a window of plus or minus 1000 inhabitants from the threshold; column 2 restricts the sample to cities in which Pharma has a $100 \%$ coverage with a polynomial of third degree and a window of plus or minus 2500 inhabitants; column 3 is based on a third degree polynomial with a window of plus or minus 3000 inhabitants and includes as controls the average monthly number of newborns, a dummy taking value 1 if the city is in a urban area, a dummy taking value 1 if the city is in Northern Italy, and per capita disposable income at the city level; column 4 reports estimates based on a local linear regression with bandwidth equal to 2000 . 
Figure 6: Continuity tests for covariates
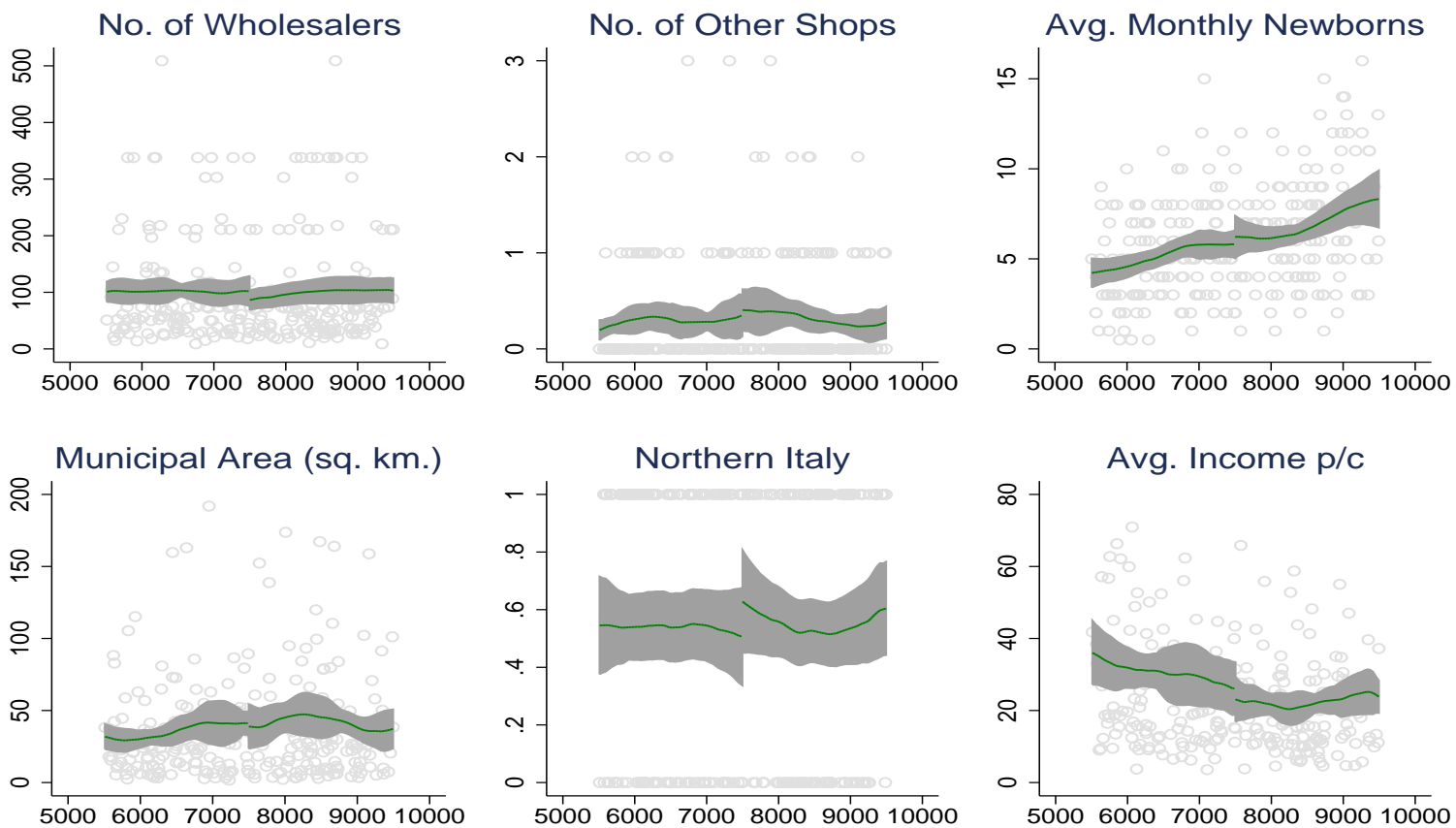

Notes: Scatter plot and local polynomial smoothing regressions (bandwith $=300$ ) of "pre-treatment" city characteristics with respect to max. historical population: no. of wholesalers in the province the city belongs to, no. of other shops competing with pharmacies, average monthly no. of newborns, dummy $=1$ if the city is in an urban area, dummy $=1$ if the city is in Northern Italy, average p.c. disposable income.

Figure 7: The monotonicity test

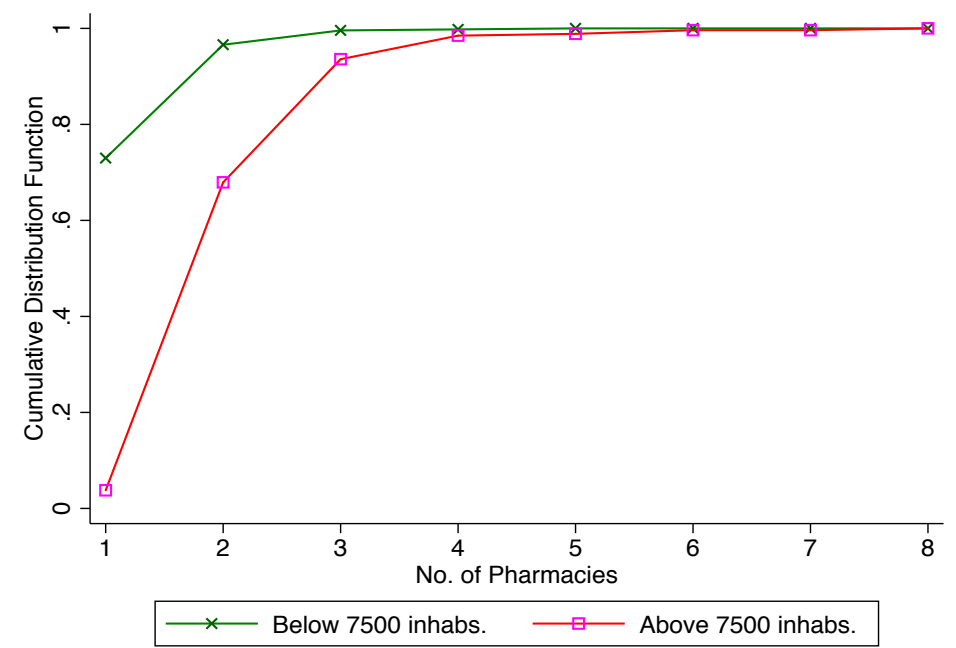

Notes: The figure reports the cumulative distribution functions of the number of pharmacies (treatment variable) for cities below and above the 7500 inhabitants threshold (the instrumental variable). Monotonicity requires that the CDF above the threshold is (weakly) greater than the CDF below (Angrist, Graddy, and Imbens, 2000). 
Figure 8: Effect of Newborns on Prices of Hygiene Products, Diapers and Milk Powders at the Threshold - Kernel-weighted Local Polynomial Smoothing Results

\section{a. Hygiene Products}
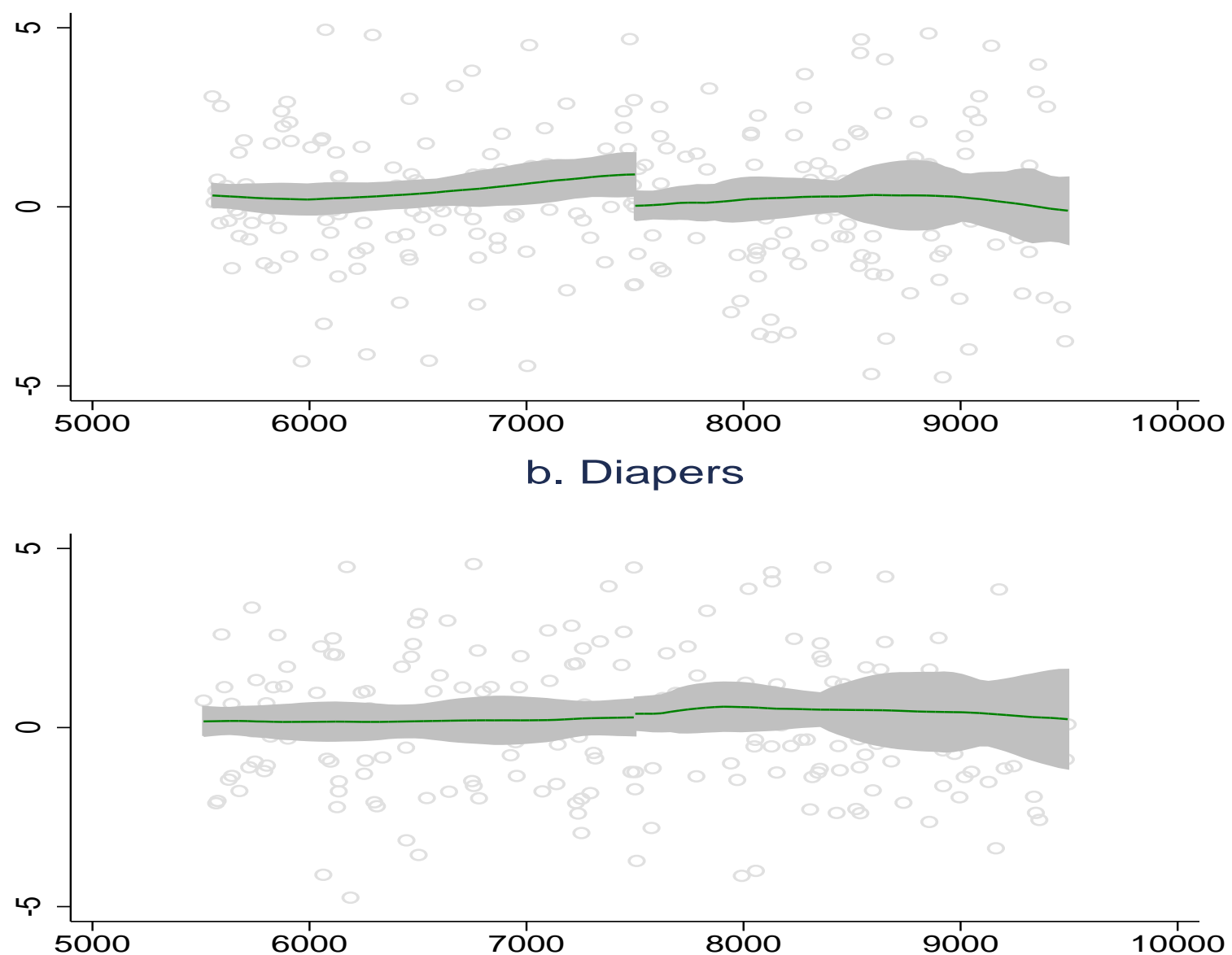

c. Milk Powders

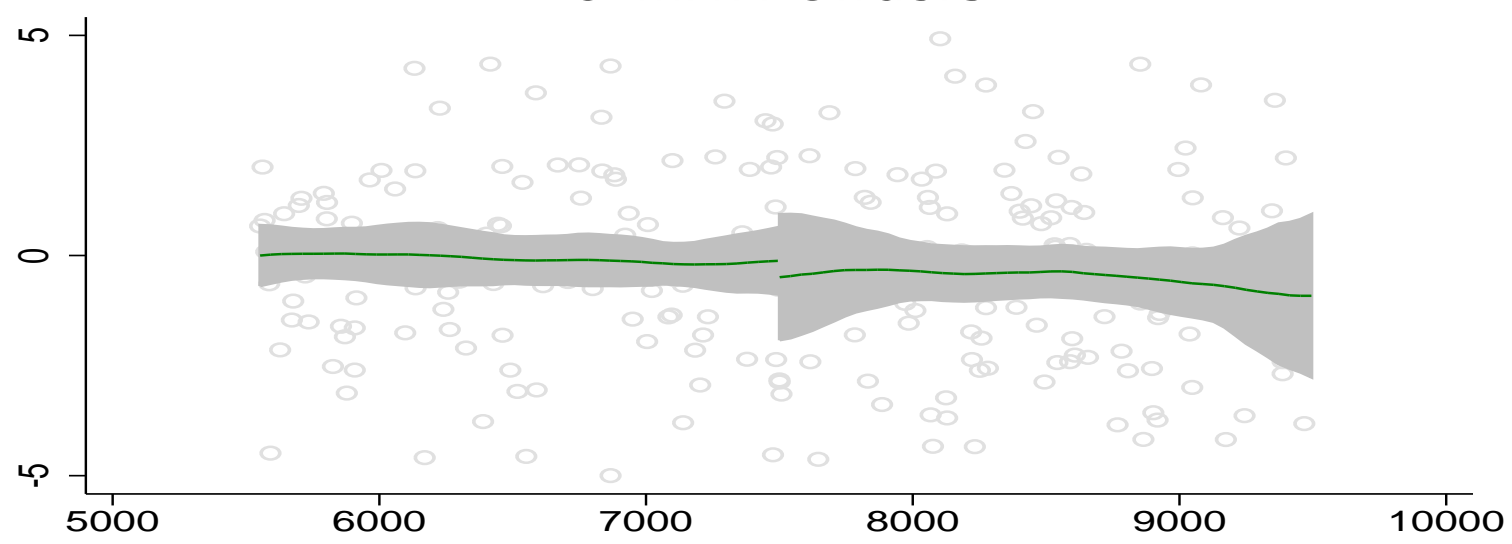

Notes: Each Panel shows the scatter plot and local polynomial smoothing regressions (bandwidth $=400$ ) of the effect of newborns on prices of hygiene products, diapers, and milk powders with respect to maximum historical population. 
Table 4: Difference-in-Discontinuities Estimates of the effect of recent newborns on prices Hygiene Products vs. Diapers

\begin{tabular}{|c|c|c|c|}
\hline & $\begin{array}{l}\text { 1st Ord. Poly } \\
\quad \pm 2000\end{array}$ & $\begin{array}{l}\text { 1st Ord. Poly } \\
\quad \pm 2500\end{array}$ & $\begin{array}{l}\text { 1st Ord. Poly } \\
\quad \pm 3000\end{array}$ \\
\hline \multirow[t]{2}{*}{$\log$-Newborns $(\theta)$} & 1.062 & 1.103 & 0.833 \\
\hline & $(0.265)^{* * *}$ & $(0.268)^{* * *}$ & $(0.218)^{* * *}$ \\
\hline \multirow[t]{2}{*}{ log-Nborns $\times$ Diaper Dummy $\left(\theta^{D}\right)$} & -0.832 & -0.768 & -0.676 \\
\hline & $(0.560)$ & $(0.382)^{* *}$ & $(0.318)^{* *}$ \\
\hline \multirow[t]{2}{*}{ log-Nborns $\times$ Threshhold Dummy $\left(\theta^{K}\right)$} & -1.208 & -0.839 & -0.613 \\
\hline & $(0.460)^{* * *}$ & $(0.382)^{*}$ & $(0.320)^{*}$ \\
\hline \multirow[t]{2}{*}{ log-Nborns $\times$ Diaper $\times$ Threshhold $\left(\theta^{D K}\right)$} & 0.213 & 0.567 & 0.550 \\
\hline & $(0.632)$ & $(0.618)$ & $(0.526)$ \\
\hline Number of observations & 20159 & 26135 & 31943 \\
\hline \multirow[t]{2}{*}{ Number of Cities } & 265 & 337 & 413 \\
\hline & $\begin{array}{l}\text { 2nd Ord. Poly } \\
\quad \pm 2500\end{array}$ & $\begin{array}{c}\text { 3rd Ord. Poly. } \\
\pm 2500\end{array}$ & $\begin{array}{c}\text { 4th Ord. Poly } \\
\quad \pm 2500\end{array}$ \\
\hline \multirow[t]{2}{*}{$\log$-Nborns $(\theta)$} & 1.122 & 0.950 & 1.225 \\
\hline & $(0.321)^{* * *}$ & $(0.402)^{* *}$ & $(0.408)^{* * *}$ \\
\hline \multirow[t]{2}{*}{ log-Nborns $\times$ Diaper Dummy $\left(\theta^{D}\right)$} & -0.769 & -0.779 & -0.760 \\
\hline & $(0.381)^{* *}$ & $(0.383)^{* *}$ & $(0.383)^{* *}$ \\
\hline \multirow[t]{2}{*}{ log-Nborns $\times$ Threshhold Dummy $\left(\theta^{K}\right)$} & -1.971 & -1.831 & -1.856 \\
\hline & $(0.586)^{* * *}$ & $(0.698)^{* * *}$ & $(0.785)^{* *}$ \\
\hline \multirow{2}{*}{ log-Nborns $\times$ Diaper $\times$ Threshhold $\left(\theta^{D K}\right)$} & 0.480 & 0.491 & 0.470 \\
\hline & $(0.586)$ & $(0.584)$ & $(0.592)$ \\
\hline Number of observations & 26135 & 26135 & 26135 \\
\hline \multirow[t]{3}{*}{ Number of cities } & 337 & 337 & 337 \\
\hline & Local-Linear & $\%$ Pharma $=100$ & With Controls \\
\hline & Bandwidth 2000 & \pm 2500 & \pm 2500 \\
\hline \multirow[t]{2}{*}{ log-Newborns $(\theta)$} & 1.041 & 1.008 & 1.103 \\
\hline & $(0.215)^{* *}$ & $(0.364)^{* * *}$ & $(0.267)^{* * *}$ \\
\hline \multirow[t]{2}{*}{ log-Nborns $\times$ Diaper Dummy $\left(\theta^{D}\right)$} & -1.260 & -0.686 & -0.768 \\
\hline & $(0.547)^{* *}$ & $(0.570)$ & $(0.382)^{* *}$ \\
\hline \multirow[t]{2}{*}{ log-Nborns $\times$ Threshhold Dummy $\left(\theta^{K}\right)$} & -0.113 & -0.769 & -0.840 \\
\hline & $(0.704)$ & $(0.675)$ & $(0.471)^{*}$ \\
\hline \multirow[t]{2}{*}{ log-Nborns $\times$ Diaper $\times$ Threshhold $\left(\theta^{D K}\right)$} & -1.147 & -0.008 & 0.567 \\
\hline & $(0.628)^{*}$ & $(1.022)$ & $(0.618)$ \\
\hline Number of observations & 9816 & 11034 & 26135 \\
\hline Number of Cities & 257 & 158 & 337 \\
\hline
\end{tabular}

Notes: Estimates of the effect of recent newborns on prices based on equation (9) estimated on the sample of pharmacies and months in which both hygiene products and diapers are sold. The controls included in the last column are: the average monthly number of newborns, a dummy taking value 1 if the city is in a urban area, a dummy taking value 1 if the city is in Northern Italy and per capita disposable income at the city level. Robust standard errors clustered at the city and time levels in parentheses. 
Table 5: Difference-in-Discontinuities Estimates of the effects of recent newborns on pricesHygiene products vs. Milk powders

\begin{tabular}{|c|c|c|c|}
\hline & $\begin{array}{l}\text { 1st Ord. Poly } \\
\quad \pm 2000\end{array}$ & $\begin{array}{l}\text { 1st Ord. Poly } \\
\quad \pm 2500\end{array}$ & $\begin{array}{l}\text { 1st Ord. Poly } \\
\quad \pm 3000\end{array}$ \\
\hline \multirow[t]{2}{*}{ log-Newborns $(\theta)$} & 0.787 & 1.035 & 0.749 \\
\hline & $(0.291)^{* * *}$ & $(0.301)^{* * *}$ & $(0.269)^{* * *}$ \\
\hline \multirow[t]{2}{*}{$\log$-Nborns $\times$ Milk Dummy $\left(\theta^{D}\right)$} & -1.105 & -0.853 & -0.774 \\
\hline & $(0.556)^{* *}$ & $(0.431)^{* *}$ & $(0.384)^{* *}$ \\
\hline \multirow[t]{2}{*}{ log-Nborns $\times$ Threshhold Dummy $\left(\theta^{K}\right)$} & -1.193 & -1.439 & -0.870 \\
\hline & $(0.550)^{* *}$ & $(0.568)^{* *}$ & $(0.516)^{*}$ \\
\hline \multirow[t]{2}{*}{ log-Nborns $\times$ Milk $\times$ Threshhold $\left(\theta^{D K}\right)$} & 0.283 & 0.373 & 0.067 \\
\hline & $(0.803)$ & $(0.764)$ & $(0.703)$ \\
\hline Number of observations & 17714 & 20340 & 23726 \\
\hline \multirow[t]{2}{*}{ Number of cities } & 265 & 337 & 413 \\
\hline & $\begin{array}{c}\text { 2nd Ord. Poly } \\
\pm 2500\end{array}$ & $\begin{array}{l}\text { 3rd Ord. Poly. } \\
\pm 2500\end{array}$ & $\begin{array}{c}\text { 4th Ord. Poly } \\
\pm 2500\end{array}$ \\
\hline \multirow[t]{2}{*}{$\log -$ Nborns $(\theta)$} & 0.948 & 0.934 & 1.348 \\
\hline & $(0.324)^{* * *}$ & $(0.367)^{* *}$ & $(0.442)^{* * *}$ \\
\hline \multirow[t]{2}{*}{$\log$-Nborns $\times$ Milk Dummy $\left(\theta^{D}\right)$} & -0.894 & -0.894 & -0.884 \\
\hline & $(0.402)^{* *}$ & $(0.402)^{* *}$ & $(0.403)^{* *}$ \\
\hline \multirow[t]{2}{*}{ log-Nborns $\times$ Threshhold Dummy $\left(\theta^{K}\right)$} & -1.780 & -2.089 & -2.548 \\
\hline & $(0.568)^{* * *}$ & $(0.619)^{* * *}$ & $(0.686)^{* * *}$ \\
\hline \multirow{2}{*}{ log-Nborns $\times$ Milk $\times$ Threshhold $\left(\theta^{D K}\right)$} & 0.023 & 0.005 & -0.006 \\
\hline & $(0.715)$ & $(0.709)$ & $(0.709)$ \\
\hline Number of observations & 22656 & 22656 & 22656 \\
\hline \multirow[t]{3}{*}{ Number of cities } & 337 & 337 & 337 \\
\hline & Local-Linear & $\%$ Pharma $=100$ & With Controls \\
\hline & Bandwidth 2000 & \pm 2500 & \pm 2500 \\
\hline \multirow[t]{2}{*}{ log-Newborns $(\theta)$} & 0.736 & 0.730 & 0.900 \\
\hline & $(0.135)^{* * *}$ & $(0.349)^{* *}$ & $(0.286)^{* * *}$ \\
\hline \multirow[t]{2}{*}{$\log$-Nborns $\times$ Milk Dummy $\left(\theta^{D}\right)$} & -1.000 & -1.159 & -0.893 \\
\hline & $(0.600)^{*}$ & $(0.524)^{* *}$ & $(0.402)^{* *}$ \\
\hline \multirow[t]{2}{*}{ log-Nborns $\times$ Threshhold Dummy $\left(\theta^{K}\right)$} & -0.439 & -0.665 & -0.959 \\
\hline & $(0.905)$ & $(0.704)$ & $(0.536)^{*}$ \\
\hline \multirow[t]{2}{*}{ log-Nborns $\times$ Milk $\times$ Threshhold $\left(\theta^{D K}\right)$} & -0.522 & -0.769 & 0.101 \\
\hline & $(0.960)$ & $(1.016)$ & $(0.731)$ \\
\hline Number of observations & 1547 & 9497 & 22656 \\
\hline Number of cities & - & 158 & 337 \\
\hline
\end{tabular}

Notes: Estimates of the effect of recent newborns on prices based on equation (9) estimated on the sample of pharmacies and months in which both hygiene products and milk powders are sold. The controls included in the last column are: the average monthly number of newborns, a dummy taking value 1 if the city is in a urban area, a dummy taking value 1 if the city is in Northern Italy and per capita disposable income at the city level. Robust standard errors clustered at the city and time levels in parentheses. 